\title{
Preclinical and Clinical Assessment of Cannabinoids as Anti-Cancer Agents
}

\author{
Daniel A. Ladin ${ }^{1}$, Eman Soliman ${ }^{1,2}$, LaToya Griffin ${ }^{1}$ and Rukiyah Van Dross ${ }^{1,3 *}$ \\ ${ }^{1}$ Department of Pharmacology and Toxicology, Brody School of Medicine, East Carolina University, Greenville, NC, USA, \\ ${ }^{2}$ Department of Pharmacology and Toxicology, Faculty of Pharmacy, Zagazig University, Zagazig, Egypt, ${ }^{3}$ Center for Health \\ Disparities, East Carolina University, Greenville, NC, USA
}

OPEN ACCESS

Edited by:

Gian Marco Leggio,

University of Catania, Italy

Reviewed by:

Elena Martín-García,

Pompeu Fabra University, Spain Sean D. McAllister,

California Pacific Medical Center

Research Institute, USA

*Correspondence:

Rukiyah Van Dross

vandrossr@ecu.edu

Specialty section:

This article was submitted to

Experimental Pharmacology and Drug

Discovery,

a section of the journal

Frontiers in Pharmacology

Received: 30 June 2016 Accepted: 20 September 2016

Published: 07 October 2016

Citation:

Ladin DA, Soliman E, Griffin L and Van Dross $R$ (2016) Preclinical and Clinical

Assessment of Cannabinoids as Anti-Cancer Agents.

Front. Pharmacol. 7:361.

doi: 10.3389/fphar.2016.00361
Cancer is the second leading cause of death in the United States with 1.7 million new cases estimated to be diagnosed in 2016. This disease remains a formidable clinical challenge and represents a substantial financial burden to the US health care system. Therefore, research and development of novel therapeutics for the treatment of cancer is of high priority. Cannabinoids and their derivatives have been utilized for their medicinal and therapeutic properties throughout history. Cannabinoid activity is regulated by the endocannabinoid system (ECS), which is comprised of cannabinoid receptors, transporters, and enzymes involved in cannabinoid synthesis and breakdown. More recently, cannabinoids have gained special attention for their role in cancer cell proliferation and death. However, many studies investigated these effects using in vitro models which may not adequately mimic tumor growth and metastasis. As such, this article aims to review study results which evaluated effects of cannabinoids from plant, synthetic and endogenous origins on cancer development in preclinical animal models and to examine the current standing of cannabinoids that are being tested in human cancer patients.

Keywords: cannabinoids, cancer, in vivo, clinical studies, clinical trials, therapeutics, cancer models, endocannabinoids

\section{CANNABINOIDS AND CANCER}

Cannabinoids are a class of hydrophobic molecules that typically bind to G-protein-coupled cannabinoid receptors, cannabinoid receptor type 1 (CB1R) or cannabinoid receptor type 2 (CB2R). Endogenously synthesized cannabinoids (endocannabinoids), cannabinoid receptors, and enzymes involved in cannabinoid formation and breakdown are collectively known as the endocannabinoid system (ECS). This system has been shown to impact different neurological and immunological processes (Zhu, 2006; Tanasescu and Constantinescu, 2010). Additionally, numerous reports demonstrate that endocannabinoids and their putative receptors play a role in the development of various malignancies (Velasco et al., 2016). Many studies investigating the effects of cannabinoids on tumor progression have been carried out in cell culture. However, due to the complexity of the tumor microenvironment, these findings do not always translate to whole animal models. As such, the goal of this review was to compile and analyze the results of studies which evaluated effects of cannabinoids on cancer development in animal models (Table 1) and to examine current knowledge regarding the impact of cannabinoids on tumor growth in humans. 


\section{IN VIVO ANIMAL TUMOR MODELS}

Animal tumor models have become a mainstay in preclinical cancer research due to their ability to produce fairly predictable tumor growth. The first tumor model used to study tumorigenesis was the chemical carcinogenesis model. This model employs the use of two known carcinogens, an initiator and promotor. Initiators are typically employed in a single dose to cause irreversible DNA damage. A promotor is given in repeated doses to increase cell proliferation and induce subsequent DNA damage (Kociba and Schwetz, 1982). Implantable or grafted tumor models are also commonly used. The major subtypes of these models are the (1) syngeneic (allograft) model, in which tumor cell lines of host origin are subcutaneously injected into immune-competent animals and (2) the xenograft model, where cells distinct from the implantation host are subcutaneously injected or grafted into immune-deficient animals (Teicher, 2006). A more technically challenging type of tumor grafting is that of the orthotopic model in which tumor cells or tissues are grafted directly into the organ or system of tumor origin (Peterson and Houghton, 2004). Patient derived xenografts offer high translational value and are created when tumor tissue of human patients is implanted into an immune-compromised animal (Jin et al., 2010). Genetically engineered mouse models (GEMMs) are also used to study carcinogenesis. In the GEMMs, transgenic mice which over-express oncogenes or dominant negative tumorsuppressor genes are often more susceptible to spontaneous tumor induction (Sharpless and Depinho, 2006). Knockout models in which the expression of specific genes is disabled in animals exposed to carcinogens also provide valuable information about mechanisms of tumor formation (Rosenberg

\footnotetext{
Abbreviations: ACF, aberrant crypt foci; 1-AG, 1- arachidonoyl glycerol; 2-AG, 2-arachidonoyl glycerol; ABDH, alpha/beta-hydrolase domain; AEA arachidonoyl ethanolamide; Akt, protein kinase B; Ang2, angiopoietin-2 Protein; AOM, azoxymethane; $\mathrm{BBB}$, blood-brain-barrier; $\mathrm{CB} 1$, cannabinoid receptor type 1; CB2 cannabinoid receptor type 2; CBD, cannabidiol; $\mathrm{CBG}$, cannabigerol; CHOP10, C/EBP-homologous protein; COX-2, cyclooxygenase-2; CNS, central nervous system; CRC, colorectal cancer; DEN, diethylnitrosamine; DMBA, dimethylbenz[a]-anthracene; DNA, deoxyribonucleic acid; ECS, endocannabinoid system; EGFR, epidermal growth factor receptor; EMT, endocannabinoid membrane transporter; ER, estrogen receptors; ER-stress, endoplasmic reticulum stress; ERK, extracellular signal-regulated kinase; FAAH, fatty acid amide hydrolase; Fas, TNF receptor superfamily; GEMMs, genetically engineered mouse models; GFAP, glial fibrillary acidic protein; GPR55, G-protein coupled receptor 55; HCC, hepatocellular carcinoma; HER2, human epidermal growth factor receptor type 2; ICAM-1, intracellular adhesion molecule-1; Id-1, inhibitor of DNA binding protein; Jnk, c-jun N-terminal kinase; LC3, Microtubule-associated protein 1A/1B-light chain 3; MAGL, monoacylglycerol lipase; MEF, mouse embryo fibroblasts; MMP, matrix metalloproteinase; mTORC, mammalian target of rapamycin complex; NMSC, non-melanoma skin cancer; NSCLC, non-small-cell lung carcinoma; P-450, cytochrome P-450; pCXCR4, phospho-CXC chemokine receptor 4; $\operatorname{PPAR} \gamma$, peroxisome proliferator-activated receptor gamma; $\mathrm{PR}$, progesterone receptor; $\mathrm{p}-\mathrm{S} 6$, phospho-S6 ribosomal protein; ROS, reactive oxygen species; S-100B, S100 calcium-binding protein B; SCLC, small-cell lung carcinoma; THC, tetrahydrocannabinol; TIMP, tissue inhibitors of metalloproteinases; TMZ, temezolamide; TPA, 12-O-tetradecanoylphorbol-13-acetate; TNBC, triple negative breast cancer; TRB3, tribbles homolog protein 3; TRPM8, transient receptor potential cation channel, subfamily $\mathrm{M}$, member 8; TRPV1, transient potential vanilloid receptor; UVB, ultraviolet light B; VEGF, vascular endothelial growth factor; VEGFR, vascular endothelial growth factor receptor.
}

et al., 2009). Each of these tumor models is distinct and possess advantages and disadvantages depending upon scientific and clinical goals.

\section{BRAIN CANCER}

It is estimated that more than 23,000 individuals will be newly diagnosed with central nervous system (CNS) cancers in 2016 (Siegel et al., 2016). There are many distinct neuronal and glial tumor types that develop in the brain. Gliomas are a CNS tumor subtype that are derived from glial tissue and account for approximately $80 \%$ of all primary malignant brain tumors (Ostrom et al., 2015). The prognosis for this neoplasm is poor with an average 5-year survival rate of $5.1 \%$. As such, novel strategies are needed to impact current therapeutic approaches. The ECS has been examined in clinical and preclinical glioma models. Several studies show that glioma tissues from rodents and humans express functional ECS components including the CB1 and CB2 receptors (Sánchez et al., 2001; Moreno et al., 2014). Furthermore, CB2 expression was found to be elevated in high grade gliomas (Sánchez et al., 2001; Ellert-Miklaszewska et al., 2007) Hence, a series of informative investigations primarily conducted by the Guzman group, have examined the effects of cannabinoids on glioma cell survival with the goal of assessing the feasibility of developing these agents as novel anti-neoplastics.

Numerous studies indicate that $\Delta^{9}$-tetrahydrocannabinol ( $\left.\Delta^{9}-\mathrm{THC}\right)$ is a potent inducer of glioma death in vivo. Utilizing a C6 glioma cell xenograft model, it was demonstrated that tumor growth was significantly reduced by $\Delta^{9}$-THC (GalveRoperh et al., 2000). Subsequent to orthotopic implantation of the C6 cells the overall survival of $\Delta^{9}$-THC treated animals was also increased. In vitro studies with the $\mathrm{C} 6$ cell line suggested that the $\Delta^{9}$-THC-induced reduction in tumor growth occurred as a consequence of increased ceramide synthesis and Erk activation. Another study showed that $\Delta^{9}$-THC reduced the growth of U87MG glioma xenografts (Salazar et al., 2009). Experimentation in the U87MG cell line determined that ceramide accumulation and the induction of ER stress proteins $\mathrm{p} 8$, CHOP10, and TRB3, were required for $\Delta^{9}$-THC-induced death. The authors further demonstrated the importance of p8 in tumor growth by utilizing transformed mouse embryo fibroblasts (MEF) in which tumor development was reduced in $\mathrm{p}^{+/+}$animals treated with $\Delta^{9}$-THC compared to vehicle treated animals. In contrast, no significant difference in tumor growth was observed in $\Delta^{9}$-THC or vehicle treated $\mathrm{p}^{-/-}$ mice suggesting that $\mathrm{p} 8$ was needed for $\Delta^{9}$-THC-mediated tumor death. In a subsequent study by this group, endoplasmic reticulum stress-mediated autophagy and cell death was observed in $\Delta^{9}$-THC treated glioma. Specifically, $\Delta^{9}$-THC caused an increase in ER stress protein, TRB3, autophagy protein, LC3, and apoptosis as well as a decrease in mTORC protein, pS6 in U87MG xenograft tumors (Salazar et al., 2009). This pattern of protein expression was also observed in glioma biopsies from 2 patients with glioblastoma multiforme treated via intracranial administration with $\Delta^{9}$-THC. In vitro experiments 
TABLE 1 | Pre-clinical assessment of cannabinoids on tumor development.

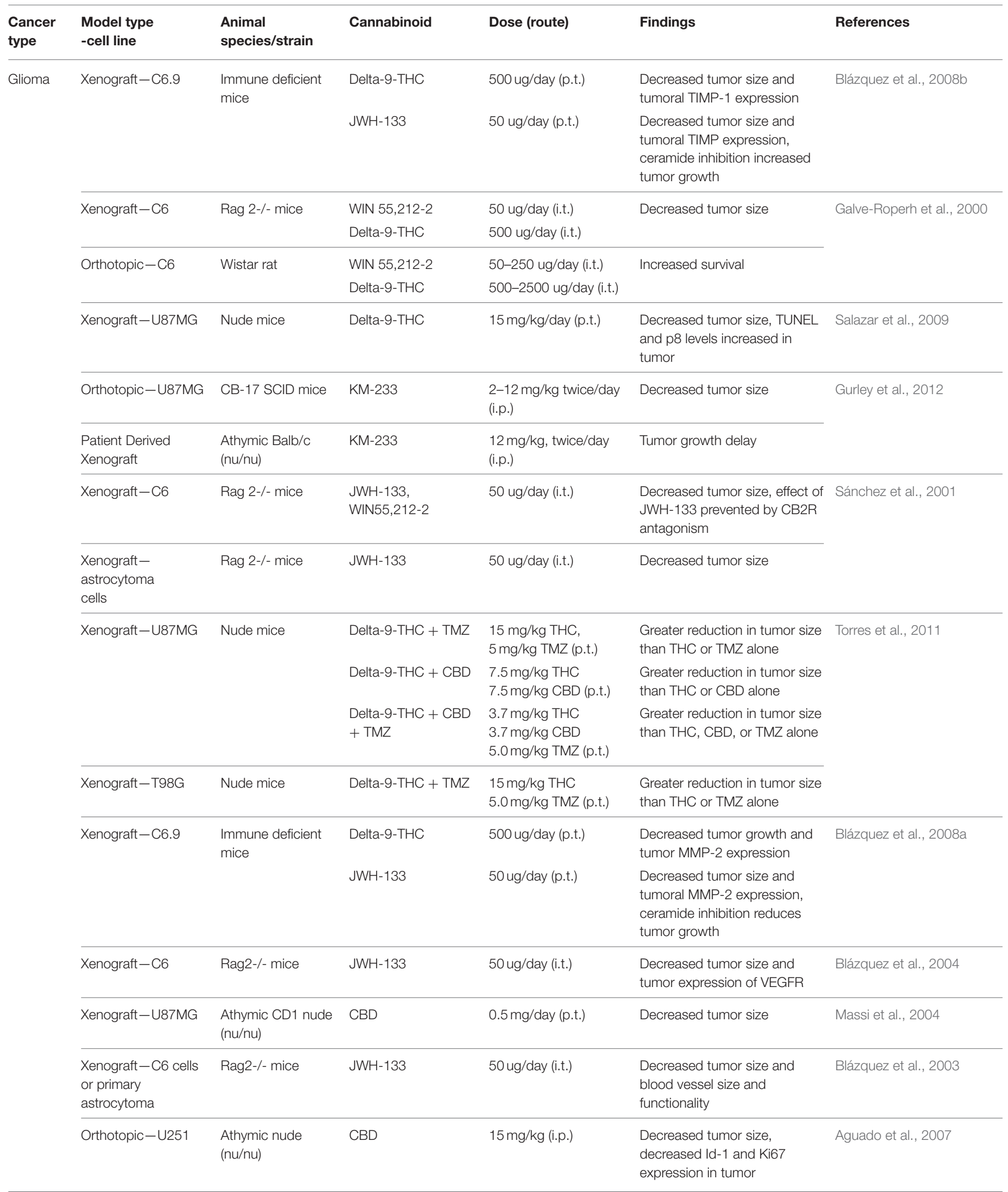


TABLE 1 | Continued

\begin{tabular}{|c|c|c|c|c|c|c|}
\hline $\begin{array}{l}\text { Cancer } \\
\text { type }\end{array}$ & $\begin{array}{l}\text { Model type } \\
\text {-cell line }\end{array}$ & $\begin{array}{l}\text { Animal } \\
\text { species/strain }\end{array}$ & Cannabinoid & Dose (route) & Findings & References \\
\hline & Xenograft & $\begin{array}{l}\text { Athymic nude } \\
\text { (nu/nu) }\end{array}$ & $\mathrm{CBD}$ & 15 mg/kg (i.p.) & $\begin{array}{l}\text { Decreased tumor size, } \\
\text { Decreased ld-1 and K167 } \\
\text { expression in tumor }\end{array}$ & Aguado et al., 2007 \\
\hline & Xenograft-U87MG & Nude mice & Delta-9-THC & 15 mg/kg/day (p.t.) & $\begin{array}{l}\text { Reduced tumor size and } \\
\text { increased TRB1, LC3, caspase } \\
3 \text {, and decreased S6 in tumors }\end{array}$ & Salazar et al., 2009 \\
\hline & Xenograft-T98G & Athymic nude & Delta-9-THC & $\begin{array}{l}1.5 \text { or } 15 \mathrm{mg} / \mathrm{kg} / \text { day } \\
\text { (p.t.) }\end{array}$ & $\begin{array}{l}\text { Decreased tumor size and } \\
\text { anti-tumor effect reversed by } \\
\text { GRP55 knockdown }\end{array}$ & Sánchez et al., 2001 \\
\hline & $\begin{array}{l}\text { Orthotopic-3832 or } \\
387 \text { cells }\end{array}$ & $\begin{array}{l}\text { Athymic nude } \\
\text { (nu/nu) }\end{array}$ & CBD & $\begin{array}{l}15 \mathrm{mg} / \mathrm{kg}, 5 \text { days } / \text { week } \\
\text { (i.p.) }\end{array}$ & $\begin{array}{l}\text { Initial decrease in tumor size } \\
\text { followed by resistance }\end{array}$ & Singer et al., 2015 \\
\hline & Xenograft-C6.9 & $\begin{array}{l}\text { Immune deficient } \\
\text { mice }\end{array}$ & Delta-9-THC & 500 ug/day (p.t.) & $\begin{array}{l}\text { Decreased tumor size and } \\
\text { MMP expression in tumor }\end{array}$ & Blázquez et al., 2008a \\
\hline & & & JWH-133 & 50 ug/day (p.t.) & $\begin{array}{l}\text { Decreased tumor size and } \\
\text { MMP expression in tumor, } \\
\text { ceramide inhibition prevented } \\
\text { tumor regression }\end{array}$ & \\
\hline \multirow[t]{6}{*}{$\begin{array}{l}\text { Colon } \\
\text { cancer }\end{array}$} & $\begin{array}{l}\text { Azoxymethane- } \\
\text { induced colon cancer } \\
\text { model }\end{array}$ & Male ICR mice & CBD & 5 mg/kg 3x weekly (i.p.) & $\begin{array}{l}\text { Reduced aberrant crypt foci } \\
\text { (ACF), number of polyps and } \\
\text { tumors }\end{array}$ & Aviello et al., 2012 \\
\hline & Xenograft-HT-29 & Nude mice & HU-331 & 5 mg/kg (i.p.) & Reduced angiogenesis & Kogan et al., 2006 \\
\hline & Xenograft-HT-29 & Nude mice & HU-331 & 5 mg/kg (i.p., s.c.,i.t.) & Reduced tumor growth & Kogan et al., 2004 \\
\hline & $\begin{array}{l}\text { General in vivo } \\
\text { toxicity }\end{array}$ & $\begin{array}{l}\text { Sabra male mice, } \\
\text { SCID-NOD Mice }\end{array}$ & HU-331 & 7.5 mg/kg (i.p.) & Less toxicity than doxorubicin & Kogan et al., 2007 \\
\hline & Xenograft-HT-29 & & male nude mice & 5 mg/kg (i.p.) & $\begin{array}{l}\text { Reduced tumor growth and } \\
\text { less cardiotoxic than } \\
\text { doxorubicin }\end{array}$ & \\
\hline & $\begin{array}{l}\text { Colitisis induced } \\
\text { colon cancer model } \\
\text { (Azoxymethane, } \\
\text { AOM+dextran sulfate } \\
\text { sodium, DSS) }\end{array}$ & Male CD1 mice & O-1602 & 3 mg/kg (i.p.) & $\begin{array}{l}\text { Reduced number and area of } \\
\text { tumors. Decreased histoscore } \\
\text { tumor burden and the } \\
\text { expression of proliferation } \\
\text { marker PCNA. Reduced key } \\
\text { mediators that link the } \\
\text { inflammation with colorectal } \\
\text { cancer such as: inflammatory } \\
\text { mediator TNF- } \alpha \text {, and } \\
\text { oncogenic transcription factors } \\
\text { STAT3 and NF } F_{k} \text { B }\end{array}$ & Kargl et al., 2013 \\
\hline
\end{tabular}




\section{TABLE 1 | Continued}

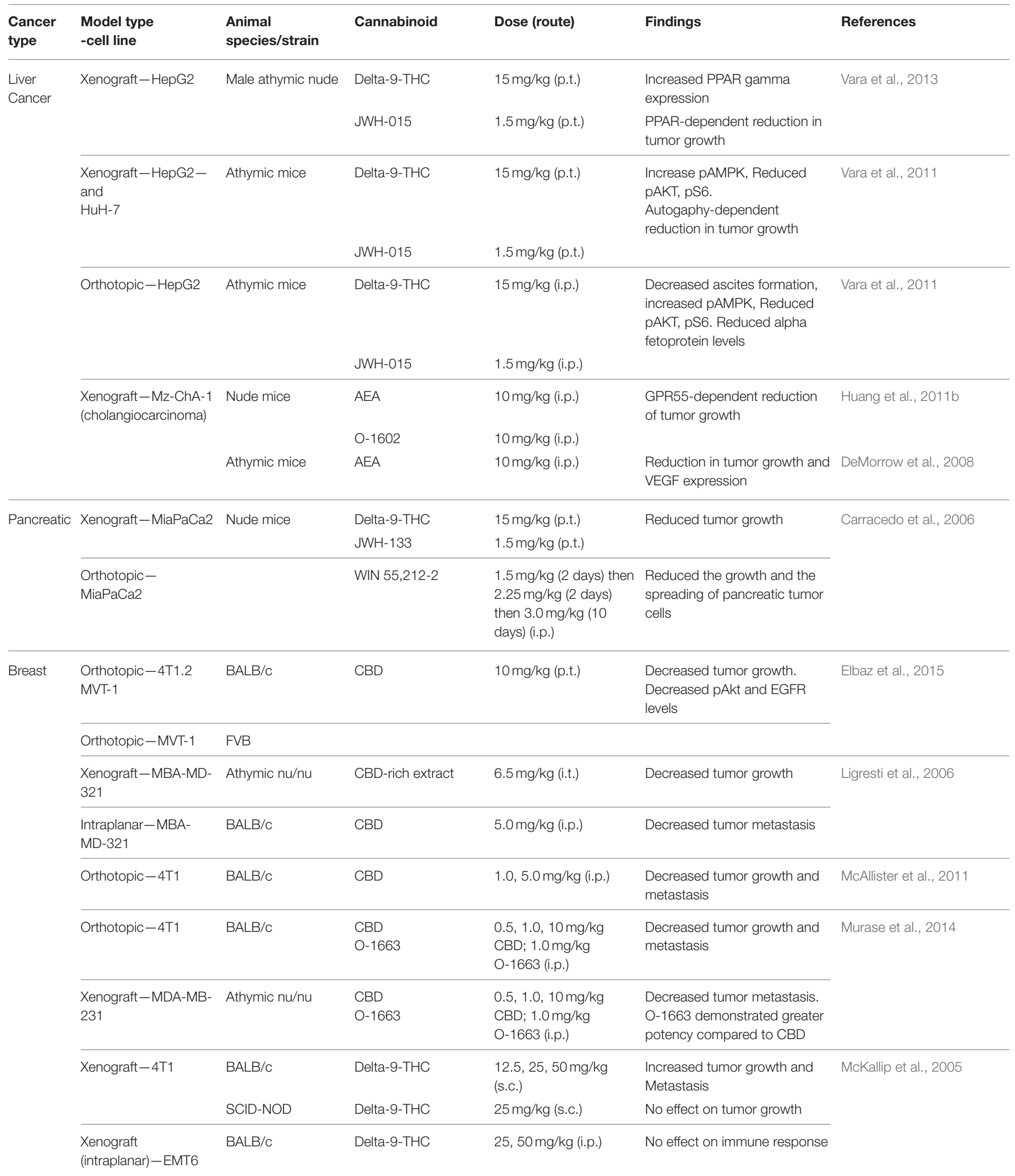




\section{TABLE 1 | Continued}

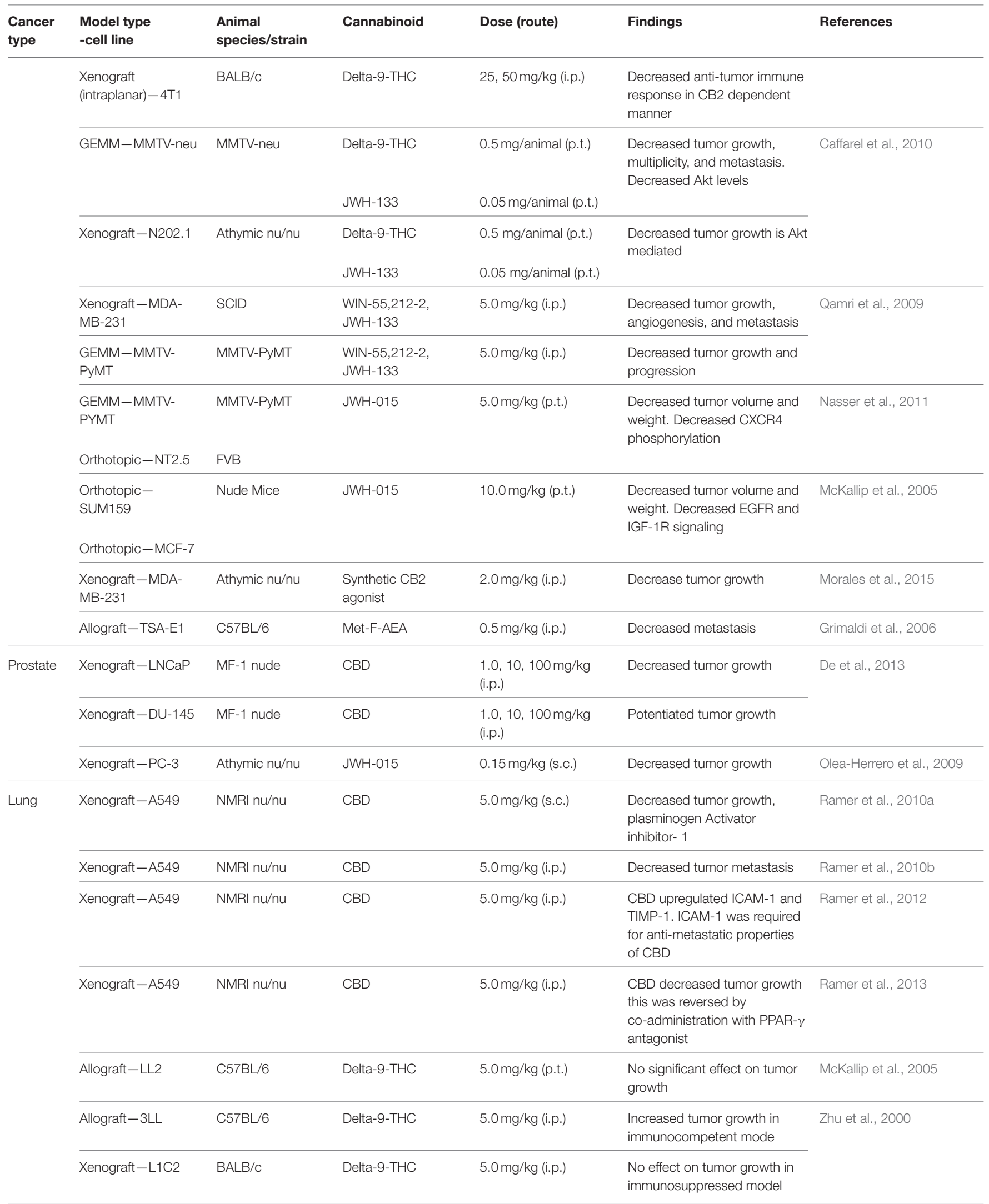




\section{TABLE 1 | Continued}

\begin{tabular}{|c|c|c|c|c|c|c|}
\hline $\begin{array}{l}\text { Cancer } \\
\text { type }\end{array}$ & $\begin{array}{l}\text { Model type } \\
\text {-cell line }\end{array}$ & $\begin{array}{l}\text { Animal } \\
\text { species/strain }\end{array}$ & Cannabinoid & Dose (route) & Findings & References \\
\hline & Xenograft-A549 & SCID & Delta-9-THC & 5.0 mg/kg (p.t.) & $\begin{array}{l}\text { Decreased Tumor growth and } \\
\text { metastasis. Decreased Akt }\end{array}$ & Preet et al., 2008 \\
\hline & Xenograft $-3 \mathrm{LL}$ & C57BL/6 & Met-F-AEA & 0.5 mg/kg (i.p.) & Decreased tumor metastasis & Bifulco et al., 2001 \\
\hline & Allograft-3LL & C57BL/6 & Met-AEA & 5.0 mg/kg (i.p.) & $\begin{array}{l}\text { Increased tumor growth in a } \\
\text { cOX-2 dependent manner }\end{array}$ & \\
\hline & Xenograft-L1C2 & $\mathrm{BALB} / \mathrm{c}$ & Met-AEA & 5.0 mg/kg (i.p.) & $\begin{array}{l}\text { Increased tumor growth in a } \\
\text { COX-2 dependent manner }\end{array}$ & Gardner et al., 2003 \\
\hline \multirow[t]{4}{*}{ Thyroid } & Xenograft-KiMol & Athymic Nude & VDM-11 & $5.0 \mathrm{mg} / \mathrm{kg}$ (i.t.) & Decreased tumor size & Bifulco et al., 2004 \\
\hline & & & AA-5-HT & 5.0 mg/kg (i.t.) & & \\
\hline & & & Met-AEA & 0.7 mg/kg (p.t.) & $\begin{array}{l}\text { Decreased tumor size, } \\
\text { anti-tumor effect blocked by } \\
\text { CB1 antagonist }\end{array}$ & Bifulco et al., 2001 \\
\hline & Xenograft-ARO cells & $\begin{array}{l}\text { Balb/c (nu/nu) nude } \\
\text { mice }\end{array}$ & JWH-133 & 50 ug/ml (i.t.) & $\begin{array}{l}\text { CB2 overexpressing ARO cells } \\
\text { reduced tumor weight vs. } \\
\text { ARO-empty vector cells }\end{array}$ & \\
\hline \multirow[t]{6}{*}{ Melanoma } & Xenograft-CHL-1 & Athymic nude mice & Delta-9-THC & 15 mg kg (p.o.) & $\begin{array}{l}\text { Reduced tumor growth, Ki67 } \\
\text { and increased TUNEL positive } \\
\text { cells }\end{array}$ & Armstrong et al., 2015 \\
\hline & $\begin{array}{l}\text { Xenograft-HCmel12 } \\
\text { (intracutaneous) }\end{array}$ & $\begin{array}{l}\text { Cnr1/2-/- mice } \\
\text { were crossed into } \\
\text { the Hgf-Cdk } 4 R 24 C \\
\text { melanoma mouse } \\
\text { model to generate } \\
\text { mice with a dark } \\
\text { skin phenotype } \\
\text { which develop CB1 } \\
\text { and CB2 } \\
\text { receptor-deficient } \\
\text { melanomas. }\end{array}$ & Delta-9-THC & 5 mg/kg (s.c.) & $\begin{array}{l}\text { CB receptors-dependent } \\
\text { reduction in tumor growth }\end{array}$ & Glodde et al., 2015 \\
\hline & Xenograft-B16 & $\begin{array}{l}\text { C57BL/6 mice and } \\
\text { Nude }\end{array}$ & WIN-55,212-2 & 50 ug/day (p.t.) & $\begin{array}{l}\text { Reduced tumor growth, cell } \\
\text { proliferation, apoptosis, and } \\
\text { angiogenesis }\end{array}$ & Blázquez et al., 2006 \\
\hline & & & JWH-133 & & & \\
\hline & $\begin{array}{l}\text { Xenograft B-16 } \\
\text { (intraplantar) }\end{array}$ & C57BL/6 mice & WIN-55,212-2 & 50 ug/day (p.t.) & $\begin{array}{l}\text { Reduced metastasis in lung } \\
\text { and liver }\end{array}$ & \\
\hline & & & $\mathrm{JWH}-133$ & & JWH-133 & \\
\hline \multirow[t]{5}{*}{ NMSC } & Xenograft-PDV.C57 & $\begin{array}{l}\text { Nude (NMRI nu) } \\
\text { mice }\end{array}$ & WIN-55,212-2 & $\begin{array}{l}6.7 \mathrm{ug} / \mathrm{ul} \text { (flow } \\
\text { pump }-0.52 \mathrm{uL} / \mathrm{h} \\
\text { (11 days) }\end{array}$ & $\begin{array}{l}\text { Inhibited skin tumor growth, } \\
\text { angiogenesis and EGFR } \\
\text { activation }\end{array}$ & Casanova et al., 2003 \\
\hline & & & JWH-133 & & & \\
\hline & $\begin{array}{l}\text { DMBA/TPA skin } \\
\text { carcinogenesis model }\end{array}$ & Female ICR mice & JWH-018 & 0.02 and $0.2 \mathrm{uM}$ (t.o.) & $\begin{array}{l}\text { Inhibited inflammation, } \\
\text { promotion of skin papillomas, } \\
\text { tumor incidence }\end{array}$ & Nakajima et al., 2013 \\
\hline & & & JWH-122 & 0.2 and $2 \mathrm{uM}$ (t.o.) & & \\
\hline & & & JWH-210 & 0.2 and $2 \mathrm{uM}$ (t.o.) & & \\
\hline
\end{tabular}

p.t., peritumor; i.t., intratumor; i.p., intraperitoneal; s.c., cubcutaneous; t.o., topical; p.o. oral. 
with the U87MG cell line suggested that $\Delta^{9}$-THC mediated activation of TRB3 was a critical link between the ER stress and autophagy pathways as TRB3 activation was needed for inactivation of Akt and the mTORC1 complex. Other reports indicated that the administration of $\Delta^{9}$-THC improves the therapeutic outcome of the clinically utilized glioma antineoplastic, temezolamide (TMZ) (Torres et al., 2011). In this study, $\Delta^{9}$-THC significantly reduced the growth of U87MG xenograft tumors treated with TMZ when compared to TMZ or $\Delta^{9}$-THC alone. Similarly, administration of $\Delta^{9}$-THC + cannabidiol (CBD) or $\Delta^{9}$-THC + CBD + TMZ significantly reduced tumorigenesis compared to the individual drugs (Torres et al., 2011). The combined drug regimen was associated with prevalent LC3 expression and cell death in U87MG tumors. The mechanism of cell death was also examined in cultured U87MG cells where inhibition of ceramide synthesis and autophagy prevented cellular cytotoxicity (Torres et al., 2011). Since each of these studies also determined that the cytotoxic effect of $\Delta^{9}$-THC was dependent on cannabinoid receptors, the findings of these reports indicate that ceramide synthesis, ER stress, autophagy and cannabinoid receptor activation are likely shared mechanism of $\Delta^{9}$-THC-induced glioma death.

Cannabinoid regulation of matrix remodeling proteins may also play a role in its anti-tumor activity. Matrix metalloproteinases (MMP) can promote or prevent tumor invasion and metastasis by degrading extracellular matrix and other cell-associated proteins (Lukaszewicz-Zajac et al., 2014). In addition, the effects of MMPs are counteracted by tissue inhibitors of metalloproteinases (TIMPs). MMPs/TIMPs also directly regulate tumor growth, tumor apoptosis and angiogenesis. An examination of the effect of $\Delta^{9}$-THC on C6.9 cell xenograft growth showed that animals treated with $\Delta^{9}$ THC contained smaller tumors with reduced MMP-2 expression in contrast control group animals (Blázquez et al., 2008a). $\Delta^{9}$-THC also reduced tumor growth and the expression of MMP-2 in tumors of $\Delta^{9}$-THC-treated patients. Cell culture studies with C6.9 cells confirmed that MMP-2 expression and cell viability were decreased as a result of $\Delta^{9}$-THC exposure (Blázquez et al., 2008a). A different study by this research group also indicated selective participation of TIMP-1 in the anti-neoplastic activity of $\Delta^{9}$-THC (Blázquez et al., 2008b). Similar to MMPs, TIMPs have both a positive and negative impact on tumor growth (Lukaszewicz-Zajac et al., 2014). In C6.9 xenografts, $\Delta^{9}$-THC decreased tumor development and tumoral TIMP-1 but had little impact on TIMP-2 or TIMP-3 expression. Selective TIMP-1 downregulation was also observed in patient tumor samples subsequent to $\Delta^{9}$-THC administration. C6.9 cell culture studies showed that $\Delta^{9}$ THC decreased TIMP-1 expression by increasing ER stress and ceramide synthesis and also demonstrated that $\Delta^{9}$ THC reduced C6.9 cell migration (Lukaszewicz-Zajac et al., 2014). These studies suggest that downregulation of MMP2 and TIMP-1 is important for $\Delta^{9}$-THC regulation of tumor size, however additional work is needed to reveal whether the reduction in these matrix modulating proteins also alters the metastatic and invasive behavior of tumor cells in vivo.
An investigation of the effects of $\Delta^{9}$-THC on human glioblastoma-T98G xenografts demonstrated concentrationdependent effects with low $\Delta^{9}$-THC concentrations causing a modest increase in tumor growth and high $\Delta^{9}$-THC concentrations promoting tumor cell death (Sánchez et al., 2001). Experiments in cultured T98G cells suggested that this effect was mediated by the formation of a functional dimeric complex between GPR55 and CB2 receptors such that low concentrations of $\Delta^{9}$-THC activated the $\mathrm{CB} 2$ receptor and Erk expression thereby promoting tumor cell growth. However, in the presence of high $\Delta^{9}$-THC concentrations, $\Delta^{9}$-THC inhibited GPR55 which blocked the CB2 receptor and Erk activation thereby inhibiting tumor cell growth. This finding is consistent with reports showing that the putative G-protein-coupled cannabinoid receptor, GPR55, is overexpressed in cancers and promotes carcinogenesis (Falasca and Ferro, 2016).

Most clinically available cancer chemotherapeutic agents demonstrate significant toxicity toward cancer and normal cells. This lack of selectivity often produces undesirable side effects that limit its therapeutic utility. $\Delta^{9}$-THC preferentially induced cell death in tumorigenic compared to non-tumorigenic astrocytes (Salazar et al., 2009). Moreover, in non-tumor bearing rats, $\Delta^{9}$ THC $(2500 \mu \mathrm{g})$ exhibited limited toxicity and did not affect animal survival, health, behavior or hematopoietic parameters (Galve-Roperh et al., 2000). These findings suggest that $\Delta^{9}$-THC will cause limited adverse effects thereby making this compound an attractive candidate for therapeutic use. Furthermore, the anti-emetic, appetite stimulating and analgesic effects of $\Delta^{9}$ THC and other cannabinoids can provide relief for important co-morbidities commonly associated with cancer and cancer chemotherapy.

Cannabidiol (CBD) is a non-psychotropic phytocannabinoid whose effect on tumor growth is being extensively explored. CBD significantly reduced U87MG xenograft growth when compared to vehicle control animals (Massi et al., 2004). An in vitro examination of the mechanism of action suggested that the induction of reactive oxygen species (ROS) and activation of the $\mathrm{CB} 2$ receptor was involved in the anti-tumor effect. However, unlike $\Delta^{9}$-THC, CBD toxicity did not appear to be regulated by $\mathrm{CB} 1$ or ceramide. Furthermore, in an orthotopic and subcutaneous tumor model, CBD significantly decreased U251 cell tumor growth (Soroceanu et al., 2013). In tumors generated by both methods, the expression of the proliferation marker, Ki67, and inhibitor of DNA binding (Id-1) protein were reduced. Id-1 is a transcription factor that prevents tumor cell differentiation and its expression is elevated in highly aggressive tumors (Ling et al., 2006). Cell culture studies showed that CBD inhibited Id-1 expression which occurred coincident with a reduction in U251 cell invasiveness (Soroceanu et al., 2013). A follow up study by this group demonstrated that $\mathrm{CBD}$ inhibited tumor growth and increased the survival of animals orthotopically implanted with primary 3832 and 387 glioblastoma cells (Singer et al., 2015). The reduction in tumor size was accompanied by decreased expression of Id- 1 and Sox2 indicating a reduction in tumor aggressiveness. Continued administration of $\mathrm{CBD}$ in this model resulted in reduced responsiveness to $\mathrm{CBD}$, increased antioxidant response gene 
expression and upregulated expression of mesenchymal markers in the tumors. Investigation of the in vitro mechanism suggested that resistance to $\mathrm{CBD}$ was primarily caused by activation of SCL7A11 (a transcriptional target of Nrf2) antioxidant signaling as inhibition of this target decreased tumor cell survival and augmented the antitumor activity of CBD. A different study revealed that $\mathrm{CBD}$ potentiated the killing effect of ionizing radiation (IR), a common clinical therapy for glioblastoma. Using an orthotopic xenograft model, CBD $+\Delta^{9}$-THC + IR significantly decreased the size of GL261 gliomas compared to CBD $+\Delta^{9}$-THC or IR alone (Scott et al., 2014). Increased TUNEL positive cells in tumors isolated from animals exposed to CBD $+\Delta^{9}$-THC + IR implicated cell death as the mechanism of tumor growth inhibition. Thus, the antitumor activity of $\Delta^{9}$-THC and CBD has been demonstrated in different in vivo tumor models and the diverse pathways by which these agents elicit death appear to favor co-administration with other chemotherapeutic agents.

Numerous studies suggest that synthetic cannabinoids such as JWH-133, WIN 55,212-2 and HU-210 are promising chemotherapeutic agents for treatment of gliomas. In murine C6 xenografts, the growth of glioma solid tumors was significantly inhibited by JWH-133 compared to control group animals (Sánchez et al., 2001). This effect was found to be mediated by the $\mathrm{CB} 2$ but not the $\mathrm{CB} 1$ receptor. In the same animal model, JWH-133 also inhibited the growth of human glioma cells. Examination of the mechanism of cytotoxicity in cultured C6 cells showed that ceramide synthesis was needed for JWH133-mediated tumor cell death. Later studies by this group validated the in vitro mechanism by demonstrating that blockade of ceramide synthesis in vivo decreased the anti-tumor activity of JWH-133 (Blázquez et al., 2008a,b). These studies also revealed that ceramide was involved in JWH-133-induced suppression of the invasion associated proteins, MMP-2 and TIMP-1. The combined reports suggest that the induction of ceramide synthesis by JWH-133 causes a reduction tumor cell survival and invasion.

The effect of synthetic cannabinoids on angiogenesis was also examined. JWH-133 reduced the growth of C6 gliomas that was accompanied by a decrease in tumoral, pro-angiogenic VEGF and VEGFR (Blázquez et al., 2004). It was determined that VEGFR levels were also downregulated in glioma biopsies from patients treated with $\Delta^{9}$-THC. In vitro studies with C6 cells demonstrated that both JWH-133 and WIN 55,212-2 decreased VEGFR2 phosphorylation and VEGF levels by increasing ceramide production. The reduction in VEGF signaling by the cannabinoids was also dependent on $\mathrm{CB} 1$ and $\mathrm{CB} 2$ receptors. A more detailed examination of the effect of cannabinoids on angiogenesis showed that JWH-133 decreased the permeability of tumor localized blood vessels as well as the growth of C6 and patient-derived glioma cells in xenograft tumor studies (Blázquez et al., 2003). Consistent with these results, the mRNA expression of the angiogenesis and metastasis-promoting proteins VEGF, Ang2 and MMP-2 were decreased by JWH-133. Furthermore, in vitro studies using HUVEC cells demonstrated that JWH133 inhibited endothelial cell migration and initiated death that was reversed by antagonism of $\mathrm{CB} 1$ and $\mathrm{CB} 2$ receptors. The findings of these reports indicate that cannabinoid prevention of angiogenesis is reliant on ceramide production and cannabinoid receptor activation.

Accumulating evidence suggests that a subpopulation of brain tumors originate from pluripotent stem-like cells (Singh et al., 2004). These undifferentiated cells are often associated with poor prognosis and highly aggressive tumor phenotypes whereas well-differentiated glial cells are typically less aggressive (Wan et al., 2011). As such, the stem-like population of U87MG cells and human gliomas were treated with JWH-133 or HU-210 and then subcutaneously implanted to examine the effect of cannabinoids on this tumor cell subtype (Aguado et al., 2007). Cannabinoid treated cells formed smaller tumors which contained low levels of stem-like stage proteins such as nestin and high levels of differentiation-associated proteins including $\beta$-tubulin III and $S-100 \beta$. Consistent with these findings, JWH-133 and HU-210 decreased the expression of nestin and increased the expression of GFAP, S-100 $\beta$ and $\beta$-tubulin III in cultured stem-like glioma cells. Hence it appears that the anti-neoplastic activity of the synthetic cannabinoids may be attributed to their ability to prevent tumor cell survival, invasion, and angiogenesis while promoting tumor cell differentiation.

KM-233 is a synthetic cannabinoid that signals through $\mathrm{CB} 1$ and $\mathrm{CB} 2$ receptors and is a derivative of $\Delta^{8}$-THC (Krishnamurthy et al., 2008). The anti-neoplastic activity of KM233 was examined in an orthotopic U87MG cell tumor protocol where a significant reduction in tumor size occurred (Gurley et al., 2012). These results were verified in a xenograft tumor study using patient-derived glioblastoma multiforme tissue. In vitro studies showed that KM-233 induced U87MG death was prevented by antagonizing the $\mathrm{CB} 1$ receptor. A subsequent study by this group confirmed the anti-tumor activity of KM233 against U87MG xenograft tumors and also demonstrated that KM-233 produced minimal damage to neuronal tissue within the therapeutic dosage range (Duntsch et al., 2006). As such, KM-233 may be an effective agent against glioma with an acceptable safety profile similar to other cannabinoids.

The bulk of our knowledge about the effect of cannabinoids on cancer growth in in vivo models is derived from the aforementioned glioma studies. Much of this work demonstrated potent antitumor activity, confirmed in vitro mechanisms of cannabinoid antitumor action and provided evidence that these molecules were minimally toxic and therefore paved the way for execution of a clinical study with a small number of glioma patients (Clinical trial ID\# NCT01812603). However, additional experimentation in animals is needed to define the pharmacokinetic properties of cannabinoids before large scale human studies are conducted. It will be particularly important to examine drug accumulation in tumors and drug disposition in body compartments subsequent to drug administration via different routes as most of the glioma studies conducted thus far employ intra/peri-tumor drug delivery. Such investigations may identify more clinically convenient routes of administration, establish the extent of drug stability and metabolism while providing clues about potential adverse effects of these agents. 


\section{DIGESTIVE SYSTEM CANCER}

Digestive system cancers include colon, stomach, liver, and pancreatic cancer. In the United States, these combined malignancies account for the highest incidence of cancer besides skin cancer and are the second leading cause of death for both sexes. In 2016, an estimated 304,930 new cases of digestive system cancer will be diagnosed in the US with 153,030 estimated deaths (Siegel et al., 2016).

\section{Colorectal Cancer}

Colorectal cancer (CRC) is the most lethal type of digestive cancer followed by pancreatic and then liver cancer. Recent studies advocate that the ECS plays a critical role in CRC development and is therefore considered an appropriate target for CRC inhibition. The levels of the endocannabinoid, anandamide (AEA), the enzymes participating in AEA biosynthesis and degradation, as well as its molecular target CB2, are elevated in tumor specimens of CRC patients (Cianchi et al., 2008; Chen et al., 2015). Furthermore, there was a positive correlation between $\mathrm{CB} 2$ receptor expression and human colon cancer growth. Consistent with this finding, the CB2 receptor was a poor prognostic marker in advanced stages of colon cancer (stage III and IV) (Martinez-Martinez et al., 2015). Hence, the ECS may significantly impact colon tumor progression. The anti-cancer activities of phyto- and synthetic cannabinoids in colon cancer animal models have also been reported. In chemically-induced azoxymethane (AOM) colon carcinogenesis, the phytocannabinoids, $\mathrm{CBD}$ and Cannabis sativa extract (which contains high $\mathrm{CBD}$ content, one of the main components of the botanical drug, Nabiximols) reduced aberrant crypt foci (ACF) formation and the number of precancerous polyps and tumors (Aviello et al., 2012; Romano et al., 2014). In vitro experiments in the same studies suggested that the cytotoxicity was mediated by CB1, TRPV1, and PPAR $\gamma$ (CBD and Cannabis extract) or CB2 (Cannabis extract) (Aviello et al., 2012; Romano et al., 2014). Furthermore, the non-psychoactive phytocannabinoid, cannabigerol (CBG), reduced the growth and development of HCT-116 xenografts and AOM-induced colon cancer formation. Using the HCT-116 cell lines, cell death was prevented by blocking TRPM8 but not CB1, CB2, or TRPV1 receptors (Borrelli et al., 2014). Synthetic cannabinoids also showed anticancer activity in different animal models. HU-331, a quinone compound synthesized from cannabidiol, reduced angiogenesis and tumor growth in a HT-29 xenograft model (Kogan et al., 2004, 2006). In nude mice xenografts with HT-29 cells, HU331 also showed greater inhibition of tumor growth than the clinically utilized chemotherapeutic, doxorubicin (Kogan et al., 2007). Moreover, a comparative study utilizing multiple animal models showed that HU-331 exhibited less cardiotoxicity than doxorubicin. In a different study, O-1662 an analog of abnormal cannabidiol, reduced the number and size of tumors formed by $\mathrm{AOM}+$ dextran sulfate sodium in the colitis-induced colon cancer model. This activity was accompanied by reduced inflammation, proliferation, and induction of apoptosis in the tumor tissue (Kargl et al., 2013). Although numerous studies tested the effect of cannabinoids and their derivatives in different
CRC models, reports that utilize agents which bind selectively to $\mathrm{CB} 1$ or $\mathrm{CB} 2$ receptors are lacking. As such, the direct role of cannabinoid receptor activation in the context of CRC treatment has not been addressed in vivo.

\section{Liver Cancer}

There are two major types of liver cancer, hepatocellular carcinoma (HCC; also known as hepatoma), which originates in hepatocytes and accounts for approximately $75 \%$ of liver cancers and cholangiocarcinoma, which develops within the bile ducts of the liver (Huang et al., 2011a). Xu et al. found that the expression of both $\mathrm{CB} 1$ and $\mathrm{CB} 2$ receptors was increased in HCC tissues and was strongly associated with improved prognosis and disease-free survival rates (Xu et al., 2006). Conversely, Mukhopadhyay et al. reported that CB1 receptors promote the initiation and progression of diethylnitrosamine (DEN)induced HCC in mice (Mukhopadhyay et al., 2015). Hence, it is appropriate to investigate whether cannabinoid receptors are suitable targets for treatment of liver cancer. Phytocannabinoid, $\Delta^{9}$-THC, and synthetic CB2 receptor agonist, JWH-015 reduced the growth of HepG2 and HuH-7-derived tumor xenografts and diminished ascites development in an orthotopic model of HCC. The anti-tumor activities of $\Delta^{9}$-THC and JWH-015 in hepatocellular carcinoma cell lines (HepG2 and $\mathrm{HuH}-7$ ) were mediated by the activation of $\mathrm{CB} 2$ receptors followed by increased ceramide, ER-stress, PPAR- $\gamma$ activity, and eventually the induction of autophagy (Vara et al., 2011, 2013). Furthermore, the endocannabinoid, AEA, reduced the growth of Mz-ChA-1derived cholangiocarcinoma xenografts and downregulated the tumor expression of angiogenic factors, VEGF-C, VEGF-R2, and VEGF-R3 in AEA-treated tumors. The anti-neoplastic activity of AEA was mediated by GPR55 receptors (in vivo and in vitro), activation of Wnt/JNK signaling (in vitro), and recruitment of the Fas death receptor into lipid rafts (in vitro) (DeMorrow et al., 2008; Huang et al., 2011b). These studies provide strong support that phyto, synthetic, and endogenous cannabinoids confer antiproliferative effects on liver tumor cells, however, in these reports xenografts are the primary model utilized. Additional insight would be gained by assessing the effect of cannabinoids on HCC using chemical carcinogenesis models which evaluate tumor growth with clinically relevant carcinogens in their native microenvironment.

\section{Pancreatic Cancer}

The ECS plays an active role in pancreatic carcinogenesis. It was reported that $\mathrm{CB} 1$ and $\mathrm{CB} 2$ receptor expression was elevated in human pancreatic tumors when compared to normal pancreas (Carracedo et al., 2006; Michalski et al., 2008). Although the levels of endocannabinoids, AEA, 1-AG, and 2-AG were unchanged in pancreatic cancer compared to normal human pancreas, high levels of CB1 receptor expression and low levels of endocannabinoid degrading enzymes, FAAH and monoacyl glycerol lipase (MAGL), were associated with shorter survival (Michalski et al., 2008). On the other hand, Carracedo et al., demonstrated that $\Delta^{9}$-THC and JWH-133 reduced growth of MiaPaCa2-derived xenografts. Additionally, WIN-55,2122 reduced the growth of orthotopically implanted MiaPaCa2 
pancreatic tumors and prevented the spread of tumor cells to distal organs (Carracedo et al., 2006). In vitro studies showed that the anti-proliferative activity of the cannabinoids was mediated by the activation of $\mathrm{CB} 2$ receptors followed by de novo synthesis of ceramide and the induction of ER-stress (Carracedo et al., 2006).

Collectively, the ECS plays an important role in the progression of digestive cancers including colon, liver, and pancreatic cancers. Cannabinoid receptor expression is elevated in tumors when compared to normal tissues, indicating that endogenous cannabinoids have cancer promoting activity. However, preclinical studies revealed that exogenous synthetic, phyto-, and endo- cannabinoids reduced tumor incidence, growth, and angiogenesis. Although sufficient evidence is not available to explain this effect, these seemingly opposing events may be explained by the biphasic effect of cannabinoids. Whereas low cannabinoid concentrations ( $<10 \mathrm{uM})$ increase tumor progression, high concentrations $(>10 \mathrm{uM})$ reduce cancer cell proliferation (Martinez-Martinez et al., 2015). Further research is required to uncover potential in vivo biphasic effects and determine the optimum drug concentrations needed to prevent pancreatic cancer growth. Moreover, since the number of pancreatic tumor studies with cannabinoids is extremely limited, more research is required to demonstrate cannabinoid efficacy.

\section{BREAST CANCER}

Breast cancer is the most commonly diagnosed cancer in women and the second leading cause of female cancer deaths in the United States (Siegel et al., 2016). Risk factors for developing this type of cancer include: being of the female sex, having a family history of this disease, obesity, and menopause-associated hormone replacement (Kaminska et al., 2015). Recent research suggested that cannabinoids and the ECS played a role in breast cancer progression and may possess therapeutic potential (Caffarel et al., 2012).

Breast cancer can be divided into three sub-types: hormone sensitive breast cancer, which expresses estrogen receptors (ER) and/or progesterone receptors (PR); HER2-positive breast cancer, which expresses human epidermal growth factor receptor (ErbB2, a member of the EGFR family); and triple negative breast cancer (TNBC), a type of breast cancer which is difficult to treat due to the lack of ER, PR, and HER2 expression. Cannabinoid receptor expression differs between these breast cancer sub-types. CB1 receptors were reported to be present in $28 \%$ of all breast carcinoma patients, with $14 \%$ being HER2 positive. On the other hand CB2 receptors were found in $72 \%$ of breast carcinomas and $91 \%$ of these tumors were HER 2 positive, suggesting a possible link between HER2 and CB2 expression (Qamri et al., 2009; Caffarel et al., 2010; Pérez-Gómez et al., 2015). Of interest, a correlation between CB2 receptor expression and breast cancer aggressiveness has been suggested (Caffarel et al., 2006). As such, the effects of cannabinoids on breast tumor growth and metastasis using in vivo models has helped elucidate their therapeutic and prognostic potential.
Phytocannabinoids such as $\Delta^{9}$-THC and CBD induce both breast cancer regression and progression in vivo, indicating that a complex interaction between these compounds and cancer exists. $\mathrm{CBD}$ was shown to decrease tumor growth in multiple breast cancer models including: two orthotopic models, one genetically engineered mouse model (GEMM) and one TNBC xenograft model (Ligresti et al., 2006; McAllister et al., 2011; Murase et al., 2014; Elbaz et al., 2015). CBD significantly decreased the incidence of lung metastasis in TNBC xenograft metastatic and orthotopic mouse models. Furthermore, two of these studies which used genetically engineered and xenograft models proposed that CBD elicited these effects by inhibiting EGFR activation, cytokine secretion, and Akt expression (McAllister et al., 2011; Elbaz et al., 2015). The CBD derivative, O-1663, was also shown to decrease TNBC xenograft growth through a mechanism requiring the generation of oxidative stress (Murase et al., 2014). Consistent with the findings for CBD, $\Delta^{9}-\mathrm{THC}$ impaired tumor growth, multiplicity and metastasis in both HER2 positive MMTV-neu mice (a GEMM) and HER2 positive xenografted mice (Caffarel et al., 2010). This group also found that downregulation of pro-tumorigenic Akt was involved in the anti-proliferative effects of $\Delta^{9}$-THC (Caffarel et al., 2010). In contrast, phytocannabinoids also promoted tumor development. The Nagarkatti group found that mice implanted with 4T1 cells that were treated with $\Delta^{9}$-THC displayed greater tumorigenicity and metastatic potential by inhibiting host anti-tumor immune responses (McKallip et al., 2005). Indeed, phytocannabinoidinduced immune suppression has been reported to be mediated by the CB2 receptor in similar tumor models (Zhu et al., 2000).

Synthetic cannabinoid receptor agonists have also been utilized to elucidate the role of $\mathrm{CB} 1$ and $\mathrm{CB} 2$ receptors in breast cancer growth. Activation of $\mathrm{CB} 1 / \mathrm{CB} 2$ receptors using WIN55,212-2 led to significant decreases in tumor growth and lung metastasis in a TNBC xenograft and a genetically engineered MMTV-PyTV (mouse mammary tumor virus encoding polyoma virus middle $\mathrm{T}$ antigen) mouse model (Qamri et al., 2009). Furthermore, selective CB2 receptor activation with JWH-133 inhibited the growth of tumors and decreased metastasis in MMTV-PyTV mice, HER2 positive MMTV-neu mice and MDAMB231-derived xenografts (Qamri et al., 2009; Caffarel et al., 2010; Morales et al., 2015). Follow-up in vitro studies performed in MDA-MB231, MDA-MB468 and N202.1 cells also suggested that $\mathrm{CB} 2$ receptor activation by synthetic cannabinoids such as JWH-133 downregulated pro-tumorigenic prostaglandin $\mathrm{E}_{2}$ $\left(\mathrm{PGE}_{2}\right)$ or Akt similar to phytocannabinoids (Qamri et al., 2009; Caffarel et al., 2010). Another CB2 receptor agonist, JWH105 , was found to inhibit tumor growth in a NT2.5-orthotopic mouse model and the MMTV-PyMT model and this observation corresponded to decreased pro-metastatic phospho-CXCR4 and phospho-ERK levels in vivo and in vitro (Nasser et al., 2011). Additionally, activation of CB2 receptors by a similar compound, JWH-015, was also found to decrease tumor growth and weight in both, ER- positive and ER- negative orthotopic models (Elbaz et al., 2016). JWH-015 treated mice exhibited decreased EGFR and IGF-1R signaling and Akt expression (Elbaz et al., 2016). Finally, the synthetic and metabolically stable analog of AEA, 2-methyl-2'F-anandamide (Met-F-AEA), was also shown 
to decrease lung metastasis in TSA-E1 cell-derived xenografts (Grimaldi et al., 2006). For the most part, in vivo studies indicate that phyto-, synthetic- and endo- cannabinoids suppress tumor development in hormone receptor positive, EGFR positive and triple negative breast cancer animal models. However, additional animal studies are needed to understand how cannabinoid regulation of the immune system impacts breast tumor growth.

\section{PROSTATE CANCER}

Carcinoma of the prostate is the development of malignant cells within the male reproductive prostate gland. It is the most commonly diagnosed cancer in all men with an estimated 180,000 new cases in 2016 (Siegel et al., 2016). This cancer type is also the second leading cause of cancer deaths in men, which primarily appears to be a result of late detection. Risk factors for developing this disease are advanced age, family history, and race.

Cannabinoids and their receptors have shown promise as potential therapeutics in prostate cancer. $\mathrm{CB} 1$ and $\mathrm{CB} 2$ receptor expression was shown to be elevated in prostate cancer compared to normal prostate tissue and are suggested to be positively correlated with poor disease outcome (Sarfaraz et al., 2005; Chung et al., 2009). Prostate cancer progression depends on androgen activity and while the ECS may influence this signaling, the interplay between these systems in the context of cancer is poorly understood (Sánchez et al., 2003a,b). Although numerous studies have evaluated the effect of cannabinoids on prostate cancer in cell culture studies, relatively few reports have determined if these effects occur in in vivo animal models. Di Marzo's group found that cannabis extracts enriched with CBD effectively decreased tumor growth in androgen receptor positive LNCaP xenografts but potentiated tumor growth of androgen receptor negative DU-145 xenografts (De et al., 2013). Furthermore, in vitro experiments using PC-3, DU-145, 22RV1, and LNCaP cell lines in this study found that CBD decreased androgen receptor expression suggesting that crosstalk between the $\mathrm{CBD}$ and androgen signaling pathways may affect tumor growth. CBD also significantly increased the generation of ROS and pro-apoptotic CHOP10 expression in these four prostate cancer cell lines (De et al., 2013). Similarly, JWH-015 led to decreased tumor proliferation in PC-3 derived xenografts. These anti-proliferative effects were examined in vitro and were suggested to be mediated by CB2 induced synthesis of ceramide (Olea-Herrero et al., 2009). While these studies show a promising role for cannabinoids in targeting prostate cancer, more research is needed to definitively establish cannabinoid efficacy in vivo and the importance of androgen receptor signaling in this system.

\section{LUNG CANCER}

Lung cancer is the most deadly neoplasm in both males and females in the United States with a death toll anticipated to exceed 150,000 individuals in 2016 (Siegel et al., 2016). The two major types of lung cancer are small-cell lung cancer (SCLC) and non-small-cell lung cancer (NSCLC). Risk factors for developing this disease are tobacco smoking, genetic predisposition, and exposure to radon gas. Survival figures from this disease powerfully demonstrate the need for novel interventions. As such, cannabinoids have been evaluated in vivo for their efficacy against lung cancer.

CB1 receptors were expressed in $24 \%$ human NSCLC tissues, while CB2 receptor expression was found in 55\% of NSCLC, suggesting a role for $\mathrm{CB}$-receptors in tumor development (Preet et al., 2011). Cannabinoids such as $\Delta^{9}$-THC, CBD and MetAEA elicited different effects in lung cancer animal models. CBD administration to mice with A549 cell xenografts decreased tumor growth, invasion and metastasis (Ramer et al., 2010a,b, 2012). Follow up in vitro experiments using A549, H358, and H460 lung cancer cell lines suggested that the anti-metastatic effect of CBD was mediated by upregulation of intracellular adhesion molecule-1 (ICAM-1), an anti-metastatic protein which has been suggested to suppress tumor growth via an immunosurveillance mechanism (Wolfram et al., 2000; Ramer et al., 2012). In another study, CBD exhibited anti-tumor effects that were reversed by co-administration of a PPAR $\gamma$ antagonist in vivo (Ramer et al., 2013). Similarly, Preet et.al. found that the phytocannabinoid, $\Delta^{9}$-THC, downregulated Akt in A549derived xenografts, which corresponded with decreased tumor growth and metastasis (Preet et al., 2008). In contrast, Zhu et al. showed that $\Delta^{9}$-THC increased the tumorigenicity of $3 \mathrm{LL}$ lung cancer cells in allografted immunocompetent mice and demonstrated that CB2 mediated inhibition of anti-tumor lymphocyte activity was the primary mechanism for accelerated tumor growth (Zhu et al., 2000). Furthermore, these investigators and the Arevalo group found that $\Delta^{9}$-THC administration had no effect on tumor growth in xenografted immunodeficient mice (Zhu et al., 2000; McKallip et al., 2005). Stable analogs of AEA also showed differential effects on lung cancer progression in vivo. The Dubinett group found that met-AEA increased tumor growth in a xenograft and allograft murine model and that COX-2 inhibition abrogated these effects (Gardner et al., 2003). Conversely, Bifulco et al. found that met-F-AEA treatment decreased tumor metastasis in a $3 \mathrm{LL}$ cell-derived xenograft model (Bifulco et al., 2001). These studies suggest that the ECS plays a role in both lung cancer progression and suppression. Consequently, several of these studies indicate that anti-tumor immunity is suppressed by certain cannabinoids, exacerbating tumor growth in immune-competent animals. As such, exploring the interplay between the immune system, the ECS and lung cancer development may be critical in determining whether cannabinoids are suitable for lung cancer treatment.

\section{THYROID CANCER}

Thyroid cancer is the most frequently diagnosed endocrine malignancy in the United States. It is estimated that more than 64,000 new cases will be identified and 1900 deaths will result from this disease (Siegel et al., 2016). Although the death rate is relatively low compared to other types of cancer, therapeutic options are needed for aggressive forms of this disease whose lethality is thought to be associated with the differentiation 
state of the tumor (Lee et al., 2016). Relatively few studies have examined the effect of cannabinoids on thyroid tumor development in vivo, but these reports showed that the ECS was expressed and was capable of modulating tumor growth (Portella et al., 2003; Bifulco et al., 2004; Shi et al., 2008). For example, the activity of a variety of ECS modulators was examined in KiMol thyroid cells which generate undifferentiated tumors in xenograft models (Bifulco et al., 2004). In this study, the endogenously synthesized cannabinoid, 2-AG reduced thyroid tumor development. Similarly, agents that inhibited the EMT (VDM-11) and blocked AEA hydrolysis (AA-5HT) prevented in vivo tumor growth. Also, the metabolically stable molecules, arvanil and met-F-AEA also produced a significant reduction in tumor growth. The results of this study suggested that manipulation of the EC system was a viable option to prevent propagation of thyroid tumor cells. Additional preclinical studies were conducted with met-F-AEA. Using the xenograft model with KiMol cells it was determined that met-F-AEA prevented thyroid tumor growth and this that effect was reversed by antagonism of the CB1 receptor (Bifulco et al., 2001). Other studies with KiMol cells confirmed the anti-tumor activity of met-F-AEA and also indicated that this agent regulated tumor angiogenesis (Portella et al., 2003). Specifically, tumors isolated from met-F-AEA treated animals contained reduced levels of VEGF and VEGF receptor compared to vehicle treated animals. Furthermore, the reduction in VEGF signaling could be prevented by blockade of $\mathrm{CB} 1$ receptor activity. In another study, the synthetic cannabinoid, JWH-133, was tested in the highly aggressive ARO cell tumor model (Shi et al., 2008). Xenograft tumor growth using ARO/CB2 cells (a CB2 receptor overexpressing thyroid cancer cell line) was inhibited in mice treated with JWH-133 compared to vehicle. Cell culture experimentation suggested that JWH-133 toxicity was mediated by the $\mathrm{CB} 2$ receptor in contrast to met-F-AEA which was reported to initiate thyroid carcinoma cell death via CB1 (Portella et al., 2003). The data collected thus far suggest that synthetic EC system modulators represent novel therapeutic targets for thyroid cancer. However, because of the scarcity of in vivo thyroid cancer studies with cannabinoids, more extensive evaluation is needed to confidently define the role of the ECS in this malignancy.

\section{SKIN CANCER}

The epidermis is comprised of different cell types including keratinocytes and melanocytes, which are the source of nonmelanoma skin cancer (NMSC) and melanoma, respectively. Skin cancer is the most common cancer in the United States with approximately 5.4 million new lesions ( 3.3 million cases) of NMSC and more than 76,000 new cases of melanoma diagnosed each year (American Cancer Society, 2016; Siegel et al., 2016). Melanoma is more deadly and aggressive than NMSC. It is estimated that over 10,000 patients will die from melanoma in 2016 (Siegel et al., 2016). Several in vitro and in vivo studies suggest that the ECS plays a vital role in melanoma and NMSC development and progression (reviewed in Soliman et al., 2016a). It has been reported that $\mathrm{CB} 1$ and $\mathrm{CB} 2$ receptors were expressed in human melanoma cell lines as well as in human cutaneous melanoma biopsies (Blázquez et al., 2006). In addition, circulating levels of the endocannabinoid, 2-AG, increased in metastatic B16F10 mouse melanoma as well as in patients with metastatic melanoma suggesting a link between the ECS and melanoma progression (Sailler et al., 2014). Furthermore, in human and murine normal keratinocytes and non-melanoma skin tumors (e.g., papilloma, basal cell carcinoma, squamous cell carcinoma) $\mathrm{CB} 1$ and $\mathrm{CB} 2$ receptors were expressed and were required for the development of NMSC in vivo (Casanova et al., 2003; Zheng et al., 2008).

\section{Melanoma}

The anti-tumor activity of phyto- and synthetic-cannabinoids against melanoma was reported in different in vivo studies using xenograft tumor models. Phytocannabinoid, $\Delta^{9}$-THC decreased proliferation, increased death and reduced the growth of CHL-1 melanoma xenografts (Armstrong et al., 2015). Using $\mathrm{CB} 1 / \mathrm{CB} 2-$ receptor deficient mice $\left(\mathrm{CB} 1 / 2^{-/-}\right)$, Glodde's group demonstrated that the anti-tumor effect of $\Delta^{9}$-THC on HCmel12 xenografts was dependent on cannabinoid receptors (Glodde et al., 2015). Synthetic cannabinoids, with different affinities for $\mathrm{CB} 1$ and $\mathrm{CB} 2$ receptors, have helped to shed light on the potential of targeting $\mathrm{CB} 1$ and $\mathrm{CB} 2$ receptors in melanoma. Mixed CB1/CB2 agonist, WIN-55212,2 decreased the progression and metastasis of B16F10 melanoma cells in mice after subcutaneous and intra-plantar implantation, respectively (Blázquez et al., 2006). Because the psychotropic effects of WIN-55212,2 are primarily mediated by the $\mathrm{CB} 1$ receptor, the anti-tumor effects of the non-psychoactive, CB2 selective cannabinoid, JWH-133 was examined. JWH-133 was as effective as WIN55212,2 in inhibiting melanoma tumor growth, suggesting that the anti-tumor activity of cannabinoids was mediated by $\mathrm{CB} 2$ receptor activation (Blázquez et al., 2006). Hence, the data generated thus far indicate that cannabinoid receptor agonists may be appropriate therapeutic targets for melanoma. Newer clinical approaches to combat melanoma involve mobilization of cytotoxic T-cells with monoclonal antibodies such as ipilimumab and nivolumab. Since cannabinoids are known immunomodulators, the effects of cannabinoids on cancer immunosurvailence must be addressed in future studies to have a complete understanding of the therapeutic potential of these molecules.

\section{Non-melanoma Skin Cancer}

Several studies report that cannabinoids and endocannabinoids have anti-cancer activity against NMSC via cannabinoid receptor dependent or independent pathways (Van Dross et al., 2013; Soliman and Van Dross, 2015; Soliman et al., 2016b). There are two well-known animal models for NMSC, the UVBlight-induced skin carcinogenesis model (Fischer et al., 2007) or the two-stage chemical carcinogenesis protocol using a tumor initiator such as dimethylbenz[a]-anthracene (DMBA) and a tumor promoter such as 12-O-tetradecanoylphorbol13-acetate (TPA) (Kiraly et al., 2016). Using CB1 and CB2 receptor deficient $\left(\mathrm{CB} 1 / 2^{-/-}\right)$and wild type $\left(\mathrm{CB} 1 / 2^{+/+}\right)$mice, it was determined that $\mathrm{CB} 1$ and $\mathrm{CB} 2$ receptors were required 
for papilloma formation initiated by UVB-light. In contrast, similar studies with $\mathrm{CB} 1 / 2^{+/+}$and $\mathrm{CB} 1 / 2^{-/-}$mice in the DMBA/TPA model demonstrated that cannabinoid receptors were not required for skin tumorigenesis. Data from these two different studies indicate that the involvement of ECS in skin cancer development is dependent on the type of the stimulus (Zheng et al., 2008; Gegotek et al., 2016). The in vivo antitumor activities of different synthetic cannabinoids have also been reported. WIN-55,212-2 and JWH-133 reduced the growth, impaired vascularization, and reduced the expression of various pro-angiogenic factors in the murine epidermal tumor cell PDV.C57 xenograft model (Casanova et al., 2003). In a different study, the anti-tumor activity of other synthetic cannabinoids was analyzed in the DMBA/TPA skin carcinogenesis model where JWH-018, JWH-122, and JWH-210 reduced tumor incidence and multiplicity compared to vehicle treated animals (Nakajima et al., 2013). Collectively, it appears that the ECS is involved in the formation of UVB-induced NMSC and that phyto- and synthetic- cannabinoids are capable of decreasing NMSC growth in different tumor models. It will be important for future investigations to include human NMSC tissue models (such as PDX) in the examination of cannabinoid activity since many of the existing reports primarily utilize mouse tissue xenograft and carcinogen-induced cancer models.

\section{ANTI-CANCER EFFECTS OF CANNABINOIDS IN HUMANS}

Human studies that investigate the pharmacotherapeutic benefits associated with the use of cannabinoid ligands focus on reductions in pain, spasticity and cognitive deficits in a number of central and peripheral nervous system disorders (Velasco et al., 2016). To date only a few cannabis-based pharmacological agents are licensed for clinical use. In Europe, Sativex ${ }^{\circledR}$ is approved for treatment of spasticity associated with multiple sclerosis and in Canada it is additionally approved as an adjunct analgesic for cancer pain. The CB1 antagonist rimonabant (Acomplia ${ }^{\circledR}$ ) was licensed for use in Europe to treat obesity and related conditions but was discontinued due to adverse effects (Fijal and Filip, 2016). In the United States and Europe, nabilone (Cesamet ${ }^{\circledR}$ ) and dronabinol (Marinol ${ }^{\circledR}$ ) are approved compounds for prevention of chemotherapy-induced nausea and vomiting. The emergence of preclinical studies that demonstrate the anti-tumor effects of cannabinoids are growing in number and have formed the basis of limited clinical studies which are beginning to shed light on the translational value of the preclinical work.

Guzman and colleagues were the first group to report a Phase I human study of the anti-metastasic effects of $\Delta^{9}$-THC. In this open-labeled two-part clinical trial, nine patients with recurrent glioblastoma who were refractory to surgery and radiotherapy were treated with intracranial $\Delta^{9}$-THC in combination with high-dose chemotherapeutic agent, temozolomide (Temodar ${ }^{\circledR}$ ). Following a washout phase (a period in a clinical trial where patients receive no active medication), the safety and tolerability of $\Delta^{9}$-THC was then compared to placebo (Clinical trial ID\# NCT01812603). The primary outcome measured was the incidence of adverse effects in patients receiving the combination of $\Delta^{9}$-THC and Temodar ${ }^{\circledR}$. Secondary measures were the progression free survival at 6 months and overall survival. Additional study outcomes have not yet been reported. $\Delta^{9}$ THC was found to reduce tumor cell growth in vitro from 2 study participants and reduce tumor cell immunostaining in these same patients. Importantly, intracranial administration of $\Delta^{9}$-THC was found to be a safe and tolerable approach with no apparent psychoactive effects (Gúzman et al., 2006). In a 2011 case report by Foroughi et al. two children with septum pellucidum/forniceal policytic astrocytomas experienced tumor regression following craniotomies and partial excision. The tumor regression occurred during the time that cannabis was inhaled by the patients (Foroughi et al., 2011). In another study, a 14-year-old female Philadelphia chromosome positive patient who had been unsuccessfully treated with "traditional" therapy (i.e., chemotherapy, bone marrow transplant and radiation) for acute lymphoblastic leukemia experienced a dose-dependent management of the condition with orally administered cannabinoid extracts (Singh and Bali, 2013). A clear limitation of the current human studies evaluating the anticancer effects of cannabinoid compounds is the small patient size. To date, no study findings have been replicated in multiple cohorts. Moreover, the measured outcomes and study designs are often variable across trials, making it difficult to compare their findings. However, despite these challenges, the evidence generated in these human studies are still informative and, when taken together with the strong in vivo animal data demonstrating anti-tumor effects of cannabinoids, offer promise for a clinical role for cannabinoids in the eradication of tumors.

\section{CONCLUSION}

To gain an understanding regarding the translational and therapeutic potential of cannabinoids, this review focused on examining the overall efficacy of these molecules in animal and human studies. The majority of in vivo animal studies discussed here indicate that cannabinoids from plant, synthetic and endogenous origin are capable of effectively decreasing tumor growth and invasion (Table 1). Furthermore, clinical studies evaluating cannabinoid efficacy in human subjects are limited, yet these studies showed that cannabinoids may be safe and effective anti-neoplastics. Because large scale clinical trials are lacking, examining the activity of cannabinoids in clinically translatable animal models (such as PDX) should be the goal of future research as this approach may provide a more accurate assessment of the therapeutic potential of cannabinoids.

This review also sought to couple in vivo animal studies with in vitro experiments in order to examine proposed cannabinoid mechanisms of action and to identify specific cellular targets. The studies reviewed herein indicate that cannabinoids elicit activity through cannabinoid receptor dependent and independent pathways. Moreover, processes such as ceramide production, ER-stress, autophagy, angiogenesis and matrix remodeling also appear to regulate the anti-tumor activity of cannabinoids. Hence, these investigations shed light on the role of cannabinoids 
on tumor growth in vivo and may ultimately pave the way for the development of novel cannabinoid therapeutics for cancer treatment.

\section{AUTHOR CONTRIBUTIONS}

DL, ES, LG, and RV contributed to the conception and design of the study, the acquisition of data, and the analysis and interpretation of the data. All authors participated in drafting

\section{REFERENCES}

Aguado, T., Carracedo, A., Julien, B., Velasco, G., Milman, G., Mechoulam, R., et al. (2007). Cannabinoids induce glioma stem-like cell differentiation and inhibit gliomagenesis. J. Biol. Chem. 282, 6854-6862. doi: 10.1074/jbc.M608900200

American Cancer Society (2016). Key Statistics for Basal and Squamous Cell Skin Cancers. Atlanta, GA: Online Source.

Armstrong, J. L., Hill, D. S., McKee, C. S., Hernandez-Tiedra, S., Lorente, M., Lopez-Valero, I., et al. (2015). Exploiting cannabinoid-induced cytotoxic autophagy to drive melanoma cell death. J. Invest. Dermatol. 135, 1629-1637. doi: $10.1038 /$ jid.2015.45

Aviello, G., Romano, B., Borrelli, F., Capasso, R., Gallo, L., Piscitelli, F., et al. (2012). Chemopreventive effect of the non-psychotropic phytocannabinoid cannabidiol on experimental colon cancer. J. Mol. Med. 90, 925-934. doi: 10.1007/s00109-011-0856-x

Bifulco, M., Laezza, C., Portella, G., Vitale, M., Orlando, P., De Petrocellis L, et al. (2001). Control by the endogenous cannabinoid system of ras oncogenedependent tumor growth. FASEB J. 15, 2745-2747. doi: 10.1096/fj.01-0320fje

Bifulco, M., Laezza, C., Valenti, M., Ligresti, A., Portella, G., and DI Marzo V. (2004). A new strategy to block tumor growth by inhibiting endocannabinoid inactivation. FASEB J. 18, 1606-1608. doi: 10.1096/fj.04-1754fje

Blázquez, C., Carracedo, A., Barrado, L., Real, P. J., Fernández-Luna, J. L., Velasco, G., et al. (2006). Cannabinoid receptors as novel targets for the treatment of melanoma. FASEB J. 20, 2633-2635. doi: 10.1096/fj.06-6638fje

Blázquez, C., Carracedo, A., Salazar, M., Lorente, M., Egia, A., González-Feria, L., et al. (2008b). Down-regulation of tissue inhibitor of metalloproteinases1 in gliomas: a new marker of cannabinoid antitumoral activity? Neuropharmacology $\quad 54, \quad 235-243 . \quad$ doi: 10.1016/j.neuropharm.2007. 06.021

Blázquez, C., Casanova, M. L., Planas, A., Gómez del, P. T., Villanueva, C., Fernández-Aceñero, M. J., et al. (2003). Inhibition of tumor angiogenesis by cannabinoids. FASEB J. 17, 529-531. doi: 10.1096/fj.02-0795fje

Blázquez, C., González-Feria, L., Alvarez, L., Haro, A., Casanova, M. L., and Guzmán, M. (2004). Cannabinoids inhibit the vascular endothelial growth factor pathway in gliomas. Cancer Res. 64, 5617-5623. doi: 10.1158/00085472.CAN-03-3927

Blázquez, C., Salazar, M., Carracedo, A., Lorente, M., Egia, A., GonzálezFeria, L., et al. (2008a). Cannabinoids inhibit glioma cell invasion by downregulating matrix metalloproteinase-2 expression. Cancer Res. 68, 1945-1952. doi: 10.1158/0008-5472.CAN-07-5176

Borrelli, F., Pagano, E., Romano, B., Panzera, S., Maiello, F., Coppola, D., et al. (2014). Colon carcinogenesis is inhibited by the TRPM8 antagonist cannabigerol, a Cannabis-derived non-psychotropic cannabinoid. Carcinogenesis 35, 2787-2797. doi: 10.1093/carcin/bgu205

Caffarel, M. M., Andradas, C., Mira, E., Pérez-Gómez, E., Cerutti, C., MorenoBueno, G., et al. (2010). Cannabinoids reduce ErbB2-driven breast cancer progression through Akt inhibition. Mol. Cancer. 9:196. doi: 10.1186/14764598-9-196

Caffarel, M. M., Andradas, C., Pérez-Gómez, E., Guzmán, M., and Sanchez, C. (2012). Cannabinoids: a new hope for breast cancer therapy? Cancer Treat. Rev. 38, 911-918. doi: 10.1016/j.ctrv.2012.06.005

Caffarel, M. M., Sarrio, D., Palacios, J., Guzmán, M., and Sánchez, C. (2006). Delta9-tetrahydrocannabinol inhibits cell cycle progression in human breast cancer cells through Cdc2 regulation. Cancer Res. 66, 6615-6621. doi: 10.1158/0008-5472.CAN-05-4566 or revising the manuscript, and all authors approved the final version of the manuscript for submission.

\section{ACKNOWLEDGMENTS}

This work was supported with funds from a Golfer's Against Cancer Grant and an Internal Seed Grant from the Division of Research and Graduate Studies, East Carolina University.

Carracedo, A., Gironella, M., Lorente, M., Garcia, S., Guzmán, M., Velasco, G., et al. (2006). Cannabinoids induce apoptosis of pancreatic tumor cells via endoplasmic reticulum stress-related genes. Cancer Res. 66, 6748-6755. doi: 10.1158/0008-5472.CAN-06-0169

Casanova, M. L., Blázquez, C., Martínez-Palacio, J., Villanueva, C., FernándezAceñero, M. J., Huffman, J. W., et al. (2003). Inhibition of skin tumor growth and angiogenesis in vivo by activation of cannabinoid receptors. J. Clin. Invest. 111, 43-50. doi: 10.1172/JCI200316116

Chen, L., Chen, H., Li, Y., Li, L., Qiu, Y., and Ren, J. (2015). Endocannabinoid and ceramide levels are altered in patients with colorectal cancer. Oncol. Rep. 34, 447-454. doi: 10.3892/or.2015.3973

Chung, S. C., Hammarsten, P., Josefsson, A., Stattin, P., Granfors, T., Egevad, L., et al. (2009). A high cannabinoid $\mathrm{CB}(1)$ receptor immunoreactivity is associated with disease severity and outcome in prostate cancer. Eur. J. Cancer 45, 174-182. doi: 10.1016/j.ejca.2008.10.010

Cianchi, F., Papucci, L., Schiavone, N., Lulli, M., Magnelli, L., Vinci, M. C., et al. (2008). Cannabinoid receptor activation induces apoptosis through tumor necrosis factor alpha-mediated ceramide de novo synthesis in colon cancer cells. Clin. Cancer Res. 14, 7691-7700. doi: 10.1158/1078-0432.CCR-08-0799

De, P. L., Ligresti, A., Schiano, M. A., Iappelli, M., Verde, R., Stott, C. G., et al. (2013). Non-THC cannabinoids inhibit prostate carcinoma growth in vitro and in vivo: pro-apoptotic effects and underlying mechanisms. Br. J. Pharmacol. 168, 79-102. doi: 10.1111/j.1476-5381.2012.02027.x

DeMorrow, S., Francis, H., Gaudio, E., Venter, J., Franchitto, A., Kopriva, S., et al. (2008). The endocannabinoid anandamide inhibits cholangiocarcinoma growth via activation of the noncanonical Wnt signaling pathway. Am. J. Physiol. Gastrointest. Liver Physiol. 295, G1150-G1158. doi: 10.1152/ajpgi.90455.2008

Duntsch, C., Divi, M. K., Jones, T., Zhou, Q., Krishnamurthy, M., Boehm, P., et al. (2006). Safety and efficacy of a novel cannabinoid chemotherapeutic, KM233, for the treatment of high-grade glioma. J. Neurooncol. 77, 143-152. doi: 10.1007/s11060-005-9031-y

Elbaz, M., Ahirwar, D., Ravi, J., Nasser, M. W., and Ganju, R. K. (2016). Novel role of cannabinoid receptor 2 in inhibiting EGF/EGFR and IGF-I/IGF-IR pathways in breast cancer. Oncotarget. doi: 10.18632/oncotarget.9408. [Epub ahead of print].

Elbaz, M., Nasser, M. W., Ravi, J., Wani, N. A., Ahirwar, D. K., Zhao, H., et al. (2015). Modulation of the tumor microenvironment and inhibition of EGF/EGFR pathway: novel anti-tumor mechanisms of Cannabidiol in breast cancer. Mol. Oncol. 9, 906-919. doi: 10.1016/j.molonc.2014.12.010

Ellert-Miklaszewska, A., Grajkowska, W., Gabrusiewicz, K., Kaminska, B., and Konarska, L. (2007). Distinctive pattern of cannabinoid receptor type II (CB2) expression in adult and pediatric brain tumors. Brain Res. 1137, 161-169. doi: 10.1016/j.brainres.2006.12.060

Falasca, M., and Ferro, R. (2016). Role of the lysophosphatidylinositol/GPR55 axis in cancer. Adv. Biol. Regul. 60, 88-93. doi: 10.1016/j.jbior.2015.10.003

Fijal, K., and Filip, M. (2016). Clinical/therapeutic approaches for cannabinoid ligands in central and peripheral nervous system diseases: mini review. Clin. Neuropharmacol. 39, 94-101. doi: 10.1097/WNF.00000000000 00132

Fischer, S. M., Pavone, A., Mikulec, C., Langenbach, R., and Rundhaug, J. E. (2007). Cyclooxygenase-2 expression is critical for chronic UV-induced murine skin carcinogenesis. Mol. Carcinog. 46, 363-371. doi: 10.1002/mc.20284

Foroughi, M., Hendson, G., Sargent, M. A., and Steinbok, P. (2011). Spontaneous regression of septum pellucidum/forniceal pilocytic astrocytomas-possible role 
of Cannabis inhalation. Childs. Nerv. Syst. 27, 671-679. doi: 10.1007/s00381011-1410-4

Galve-Roperh, I., Sánchez, C., Cortés, M. L., Gómez del, P. T., Izquierdo, M., and Guzman, M. (2000). Anti-tumoral action of cannabinoids: involvement of sustained ceramide accumulation and extracellular signal-regulated kinase activation. Nat. Med. 6, 313-319. doi: 10.1038/73171

Gardner, B., Zhu, L. X., Sharma, S., Tashkin, D. P., and Dubinett, S. M. (2003). Methanandamide increases COX-2 expression and tumor growth in murine lung cancer. FASEB J. 17, 2157-2159. doi: 10.1096/fj.03-0254fje

Gegotek, A., Biernacki, M., Ambrozewicz, E., Surazynski, A., Wronski, A., and Skrzydlewska, E. (2016). The cross-talk between electrophiles, antioxidant defence and the endocannabinoid system in fibroblasts and keratinocytes after UVA and UVB irradiation. J. Dermatol. Sci. 81, 107-117. doi: 10.1016/j.jdermsci.2015.11.005

Glodde, N., Jakobs, M., Bald, T., Tüting, T., and Gaffal, E. (2015). Differential role of cannabinoids in the pathogenesis of skin cancer. Life Sci. 138, 35-40. doi: 10.1016/j.lfs.2015.04.003

Grimaldi, C., Pisanti, S., Laezza, C., Malfitano, A. M., Santoro, A., Vitale, M., et al. (2006). Anandamide inhibits adhesion and migration of breast cancer cells. Exp. Cell Res. 312, 363-373. doi: 10.1016/j.yexcr.2005.10.024

Gurley, S. N., Abidi, A. H., Allison, P., Guan, P., Duntsch, C., Robertson, J. H., et al. (2012). Mechanism of anti-glioma activity and in vivo efficacy of the cannabinoid ligand KM-233. J. Neurooncol. 110, 163-177. doi: 10.1007/s11060012-0958-5

Gúzman, M., Duarte, M. J., Blázquez, C., Ravina, J., Rosa, M. C., Galve-Roperh, I., et al. (2006). A pilot clinical study of Delta9-tetrahydrocannabinol in patients with recurrent glioblastoma multiforme. Br. J. Cancer. 95, 197-203. doi: $10.1038 /$ sj.bjc. 6603236

Huang, L., Quinn, M. A., Frampton, G. A., Golden, L. E., and DeMorrow, S. (2011a). Recent advances in the understanding of the role of the endocannabinoid system in liver diseases. Dig. Liver Dis. 43, 188-193. doi: 10.1016/j.dld.2010.08.010

Huang, L., Ramirez, J. C., Frampton, G. A., Golden, L. E., Quinn, M. A., Pae, H. Y., et al. (2011b). Anandamide exerts its antiproliferative actions on cholangiocarcinoma by activation of the GPR55 receptor. Lab. Invest. 91, 1007-1017. doi: 10.1038/labinvest.2011.62

Jin, K., Teng, L., Shen, Y., He, K., Xu, Z., and Li, G. (2010). Patient-derived human tumour tissue xenografts in immunodeficient mice: a systematic review. Clin. Transl. Oncol. 12, 473-480. doi: 10.1007/s12094-010-0540-6

Kaminska, M., Ciszewski, T., Lopacka-Szatan, K., Miotla, P., and Staroslawska, E. (2015). Breast cancer risk factors. Prz Menopauzalny 14, 196-202. doi: $10.5114 / \mathrm{pm} .2015 .54346$

Kargl, J., Haybaeck, J., Stancic, A., Andersen, L., Marsche, G., Heinemann, A., et al. (2013). O-1602, an atypical cannabinoid, inhibits tumor growth in colitis-associated colon cancer through multiple mechanisms. J. Mol. Med. 91, 449-458. doi: 10.1007/s00109-012-0957-1

Kiraly, A. J., Soliman, E., Jenkins, A., and Van Dross, R. T. (2016). Apigenin inhibits COX-2, PGE2, and EP1 and also initiates terminal differentiation in the epidermis of tumor bearing mice. Prostaglandins Leukot. Essent. Fatty Acids. 104, 44-53. doi: 10.1016/j.plefa.2015.11.006

Kociba, R. J., and Schwetz, B. A. (1982). Toxicity of 2, 3, 7, 8-tetrachlorodibenzop-dioxin (TCDD). Drug Metab. Rev. 13, 387-406. doi: 10.3109/0360 2538209029986

Kogan, N. M., Blazquez, C., Alvarez, L., Gallily, R., Schlesinger, M., Guzman, M., et al. (2006). A cannabinoid quinone inhibits angiogenesis by targeting vascular endothelial cells. Mol. Pharmacol. 70, 51-59. doi: 10.1124/mol.105.021089

Kogan, N. M., Rabinowitz, R., Levi, P., Gibson, D., Sandor, P., Schlesinger, M., et al. (2004). Synthesis and antitumor activity of quinonoid derivatives of cannabinoids. J. Med. Chem. 47, 3800-3806. doi: 10.1021/jm040042o

Kogan, N. M., Schlesinger, M., Peters, M., Marincheva, G., Beeri, R., and Mechoulam, R. (2007). A cannabinoid anticancer quinone, HU-331, is more potent and less cardiotoxic than doxorubicin: a comparative in vivo study. J. Pharmacol. Exp. Ther. 322, 646-653. doi: 10.1124/jpet.107. 120865

Krishnamurthy, M., Gurley, S., and Moore, B. M. (2008). Exploring the substituent effects on a novel series of C1'-dimethyl-aryl Delta8-tetrahydrocannabinol analogs. Bioorg. Med. Chem. 16, 6489-6500. doi: 10.1016/j.bmc.200 8.05 .034
Lee, D. Y., Won, J. K., Lee, S. H., Park, D. J., Jung, K. C., Sung, M. W., et al. (2016). Changes of clinicopathologic characteristics and survival outcomes of anaplastic and poorly differentiated thyroid carcinoma. Thyroid 26, 404-413. doi: 10.1089/thy.2015.0316

Ligresti, A., Moriello, A. S., Starowicz, K., Matias, I., Pisanti, S., De, P. L., et al. (2006). Antitumor activity of plant cannabinoids with emphasis on the effect of cannabidiol on human breast carcinoma. J. Pharmacol. Exp. Ther. 318, 1375-1387. doi: 10.1124/jpet.106.105247

Ling, M. T., Wang, X., Zhang, X., and Wong, Y. C. (2006). The multiple roles of Id-1 in cancer progression. Differentiation 74, 481-487. doi: 10.1111/j.14320436.2006.00083.x

Lukaszewicz-Zajac, M., Mroczko, B., Kornhuber, J., and Lewczuk, P. (2014). Matrix metalloproteinases (MMPs) and their tissue inhibitors (TIMPs) in the tumors of central nervous system (CNS). J. Neural Transm. (Vienna). 121, 469-477. doi: 10.1007/s00702-013-1143-5

Martínez-Martínez, E., Gómez, I., Martín, P., Sánchez, A., Román, L., Tejerina, E., et al. (2015). Cannabinoids receptor type 2, CB2, expression correlates with human colon cancer progression and predicts patient survival. Oncoscience 2, 131-141. doi: 10.18632/oncoscience.119

Massi, P., Vaccani, A., Ceruti, S., Colombo, A., Abbracchio, M. P., and Parolaro, D. (2004). Antitumor effects of cannabidiol, a nonpsychoactive cannabinoid, on human glioma cell lines. J. Pharmacol. Exp. Ther. 308, 838-845. doi: 10.1124/jpet.103.061002

McAllister, S. D., Murase, R., Christian, R. T., Lau, D., Zielinski, A. J., Allison, J., et al. (2011). Pathways mediating the effects of cannabidiol on the reduction of breast cancer cell proliferation, invasion, and metastasis. Breast Cancer Res. Treat. 129, 37-47. doi: 10.1007/s10549-010-1177-4

McKallip, R. J., Nagarkatti, M., and Nagarkatti, P. S. (2005). Delta-9tetrahydrocannabinol enhances breast cancer growth and metastasis by suppression of the antitumor immune response. J. Immunol. 174, 3281-3289. doi: 10.4049/jimmunol.174.6.3281

Michalski, C. W., Oti, F. E., Erkan, M., Sauliunaite, D., Bergmann, F., Pacher, P., et al. (2008). Cannabinoids in pancreatic cancer: correlation with survival and pain. Int. J. Cancer. 122, 742-750. doi: 10.1002/ijc.23114

Morales, P., Blasco-Benito, S., Andradas, C., Gómez-Cañas, M., Flores, J. M., Goya, P., et al. (2015). Selective, nontoxic $\mathrm{CB}(2)$ cannabinoid o-quinone with in vivo activity against triple-negative breast cancer. J. Med. Chem. 58, 2256-2264. doi: 10.1021/acs.jmedchem.5b00078

Moreno, E., Andradas, C., Medrano, M., Caffarel, M. M., Pérez-Gómez, E., Blasco-Benito, S., et al. (2014). Targeting CB2-GPR55 receptor heteromers modulates cancer cell signaling. J. Biol. Chem. 289, 21960-21972. doi: 10.1074/jbc.M114.561761

Mukhopadhyay, B., Schuebel, K., Mukhopadhyay, P., Cinar, R., Godlewski, G., Xiong, K., et al. (2015). Cannabinoid receptor 1 promotes hepatocellular carcinoma initiation and progression through multiple mechanisms. Hepatology 61, 1615-1626. doi: 10.1002/hep.27686

Murase, R., Kawamura, R., Singer, E., Pakdel, A., Sarma, P., Judkins, J., et al. (2014). Targeting multiple cannabinoid anti-tumour pathways with a resorcinol derivative leads to inhibition of advanced stages of breast cancer. Br. J. Pharmacol. 171, 4464-4477. doi: 10.1111/bph.12803

Nakajima, J., Nakae, D., and Yasukawa, K. (2013). Structure-dependent inhibitory effects of synthetic cannabinoids against 12-O-tetradecanoylphorbol-13acetate-induced inflammation and skin tumour promotion in mice. J. Pharm. Pharmacol. 65, 1223-1230. doi: 10.1111/jphp.12082

Nasser, M. W., Qamri, Z., Deol, Y. S., Smith, D., Shilo, K., Zou, X., et al. (2011). Crosstalk between chemokine receptor CXCR4 and cannabinoid receptor CB2 in modulating breast cancer growth and invasion. PLoS ONE 6:e23901. doi: 10.1371/journal.pone.0023901

Olea-Herrero, N., Vara, D., Malagarie-Cazenave, S., and Díaz-Laviada, I. (2009) Inhibition of human tumour prostate $\mathrm{PC}-3$ cell growth by cannabinoids $\mathrm{R}(+)$ Methanandamide and JWH-015: involvement of CB2. Br. J. Cancer. 101, 940-950. doi: 10.1038/sj.bjc.6605248

Ostrom, Q. T., Gittleman, H., Fulop, J., Liu, M., Blanda, R., Kromer, C., et al. (2015). CBTRUS statistical report: primary brain and central nervous system tumors diagnosed in the United States in 2008-2012. Neuro Oncol. 17(Suppl. 4), iv1-iv62. doi: 10.1093/neuonc/nov189

Pérez-Gómez, E., Andradas, C., Blasco-Benito, S., Caffarel, M. M., García-Taboada, E., Villa-Morales, M., et al. (2015). Role of cannabinoid receptor CB2 in HER2 
pro-oncogenic signaling in breast cancer. J. Natl. Cancer Inst. 107:djv077. doi: 10.1093/jnci/djv077

Peterson, J. K., and Houghton, P. J. (2004). Integrating pharmacology and in vivo cancer models in preclinical and clinical drug development. Eur. J. Cancer 40, 837-844. doi: 10.1016/j.ejca.2004.01.003

Portella, G., Laezza, C., Laccetti, P., De Petrocellis L., Di Marzo V., and Bifulco, M. (2003). Inhibitory effects of cannabinoid CB1 receptor stimulation on tumor growth and metastatic spreading: actions on signals involved in angiogenesis and metastasis. FASEB J. 17, 1771-1773. doi: 10.1096/fj.02-1129fje

Preet, A., Ganju, R. K., and Groopman, J. E. (2008). Delta9-Tetrahydrocannabinol inhibits epithelial growth factor-induced lung cancer cell migration in vitro as well as its growth and metastasis in vivo. Oncogene 27, 339-346. doi: 10.1038/sj.onc. 1210641

Preet, A., Qamri, Z., Nasser, M. W., Prasad, A., Shilo, K., Zou, X., et al. (2011). Cannabinoid receptors, $\mathrm{CB} 1$ and $\mathrm{CB} 2$, as novel targets for inhibition of nonsmall cell lung cancer growth and metastasis. Cancer Prev. Res. (Phila). 4, 65-75. doi: 10.1158/1940-6207.CAPR-10-0181

Qamri, Z., Preet, A., Nasser, M. W., Bass, C. E., Leone, G., Barsky, S. H., et al. (2009). Synthetic cannabinoid receptor agonists inhibit tumor growth and metastasis of breast cancer. Mol. Cancer Ther. 8, 3117-3129. doi: 10.1158/1535-7163.MCT09-0448

Ramer, R., Bublitz, K., Freimuth, N., Merkord, J., Rohde, H., Haustein, M., et al. (2012). Cannabidiol inhibits lung cancer cell invasion and metastasis via intercellular adhesion molecule-1. FASEB J. 26, 1535-1548. doi: 10.1096/fj.11198184

Ramer, R., Heinemann, K., Merkord, J., Rohde, H., Salamon, A., Linnebacher, M., et al. (2013). COX-2 and PPAR-gamma confer cannabidiol-induced apoptosis of human lung cancer cells. Mol. Cancer Ther. 12, 69-82. doi: 10.1158/15357163.MCT-12-0335

Ramer, R., Merkord, J., Rohde, H., and Hinz, B. (2010b). Cannabidiol inhibits cancer cell invasion via upregulation of tissue inhibitor of matrix metalloproteinases-1. Biochem. Pharmacol. 79, 955-966. doi: 10.1016/j.bcp.2009.11.007

Ramer, R., Rohde, A., Merkord, J., Rohde, H., and Hinz, B. (2010a). Decrease of plasminogen activator inhibitor-1 may contribute to the anti-invasive action of cannabidiol on human lung cancer cells. Pharm. Res. 27, 2162-2174. doi: 10.1007/s11095-010-0219-2

Romano, B., Borrelli, F., Pagano, E., Cascio, M. G., Pertwee, R. G., and Izzo, A. A. (2014). Inhibition of colon carcinogenesis by a standardized Cannabis sativa extract with high content of cannabidiol. Phytomedicine 21, 631-639. doi: 10.1016/j.phymed.2013.11.006

Rosenberg, D. W., Giardina, C., and Tanaka, T. (2009). Mouse models for the study of colon carcinogenesis. Carcinogenesis 30, 183-196. doi: $10.1093 /$ carcin/bgn267

Sailler, S., Schmitz, K., Jäger, E., Ferreiros, N., Wicker, S., Zschiebsch, K., et al. (2014). Regulation of circulating endocannabinoids associated with cancer and metastases in mice and humans. Oncoscience 1, 272-282. doi: 10.18632/oncoscience.33

Salazar, M., Carracedo, A., Salanueva, I. J., Hernández-Tiedra, S., Lorente, M., Egia, A., et al. (2009). Cannabinoid action induces autophagy-mediated cell death through stimulation of ER stress in human glioma cells. J. Clin. Invest. 119, 1359-1372. doi: 10.1172/JCI37948

Sánchez, C., de Ceballos, M. L., Gomez del, P. T., Rueda, D., Corbacho, C., Velasco, G., et al. (2001). Inhibition of glioma growth in vivo by selective activation of the $\mathrm{CB}(2)$ cannabinoid receptor. Cancer Res. 61, 5784-5789.

Sánchez, M. G., Ruiz-Llorente, L., Sánchez, A. M., and Díaz-Laviada, I. (2003a). Activation of phosphoinositide 3-kinase/PKB pathway by $\mathrm{CB}(1)$ and $\mathrm{CB}(2)$ cannabinoid receptors expressed in prostate PC-3 cells. Involvement in Raf-1 stimulation and NGF induction. Cell. Signal. 15, 851-859. doi: 10.1016/S08986568(03)00036-6

Sánchez, M. G., Sánchez, A. M., Ruiz-Llorente, L., and Díaz-Laviada, I. (2003b). Enhancement of androgen receptor expression induced by (R)methanandamide in prostate LNCaP cells. FEBS Lett. 555, 561-566. doi: 10.1016/S0014-5793(03)01349-8

Sarfaraz, S., Afaq, F., Adhami, V. M., and Mukhtar, H. (2005). Cannabinoid receptor as a novel target for the treatment of prostate cancer. Cancer Res. 65, 1635-1641. doi: 10.1158/0008-5472.CAN-04-3410
Scott, K. A., Dalgleish, A. G., and Liu, W. M. (2014). The combination of cannabidiol and Delta9-tetrahydrocannabinol enhances the anticancer effects of radiation in an orthotopic murine glioma model. Mol. Cancer Ther. 13, 2955-2967. doi: 10.1158/1535-7163.MCT-14-0402

Sharpless, N. E., and Depinho, R. A. (2006). The mighty mouse: genetically engineered mouse models in cancer drug development. Nat. Rev. Drug Discov. 5, 741-754. doi: 10.1038/nrd2110

Shi, Y., Zou, M., Baitei, E. Y., Alzahrani, A. S., Parhar, R. S., Al-Makhalafi, Z., et al. (2008). Cannabinoid 2 receptor induction by IL-12 and its potential as a therapeutic target for the treatment of anaplastic thyroid carcinoma. Cancer Gene Ther. 15, 101-107. doi: 10.1038/sj.cgt.7701101

Siegel, R. L., Miller, K. D., and Jemal, A. (2016). Cancer statistics, 2016. CA Cancer J. Clin. 66, 7-30. doi: 10.3322/caac. 21332

Singer, E., Judkins, J., Salomonis, N., Matlaf, L., Soteropoulos, P., McAllister, S., et al. (2015). Reactive oxygen species-mediated therapeutic response and resistance in glioblastoma. Cell Death Dis. 6:e1601. doi: 10.1038/cddis. 2014.566

Singh, S. K., Hawkins, C., Clarke, I. D., Squire, J. A., Bayani, J., Hide, T., et al. (2004). Identification of human brain tumour initiating cells. Nature 432, 396-401. doi: 10.1038/nature03128

Singh, Y., and Bali, C. (2013). Cannabis extract treatment for terminal acute lymphoblastic leukemia with a Philadelphia chromosome mutation. Case Rep. Oncol. 6, 585-592. doi: 10.1159/000356446

Soliman, E., Henderson, K. L., Danell, A. S., and Van Dross, R. (2016b). Arachidonoyl-ethanolamide activates endoplasmic reticulum stress-apoptosis in tumorigenic keratinocytes: role of cyclooxygenase-2 and novel J-series prostamides. Mol. Carcinog. 55, 117-130. doi: 10.1002/mc.22257

Soliman, E., Ladin, D. A., and Van Dross, R. (2016a). Cannabinoids as therapeutics for non-melanoma and melanoma skin cancer. J. Dermatol. Clin. Res. 4, 1069-1076. Available online at: http://www.jscimedcentral.com/Dermatology/ dermatology-4-1069.pdf

Soliman, E., and Van Dross, R. (2015). Anandamide-induced endoplasmic reticulum stress and apoptosis are mediated by oxidative stress in nonmelanoma skin cancer: receptor-independent endocannabinoid signaling. Mol. Carcinog. doi: 10.1002/mc.22429. [Epub ahead of print].

Soroceanu, L., Murase, R., Limbad, C., Singer, E., Allison, J., Adrados, I., et al. (2013). Id-1 is a key transcriptional regulator of glioblastoma aggressiveness and a novel therapeutic target. Cancer Res. 73, 1559-1569. doi: 10.1158/00085472.CAN-12-1943

Tanasescu, R., and Constantinescu, C. S. (2010). Cannabinoids and the immune system: an overview. Immunobiology 215, 588-597. doi: 10.1016/j.imbio.2009.12.005

Teicher, B. A. (2006). Tumor models for efficacy determination. Mol. Cancer Ther. 5, 2435-2443. doi: 10.1158/1535-7163.MCT-06-0391

Torres, S., Lorente, M., Rodríguez-Fornés, F., Hernández-Tiedra, S., Salazar, M., García-Taboada, E., et al. (2011). A combined preclinical therapy of cannabinoids and temozolomide against glioma. Mol. Cancer Ther. 10, 90-103. doi: 10.1158/1535-7163.MCT-10-0688

Van Dross, R., Soliman, E., Jha, S., Johnson, T., and Mukhopadhyay, S. (2013). Receptor-dependent and receptor-independent endocannabinoid signaling: a therapeutic target for regulation of cancer growth. Life Sci. 92, 463-466. doi: 10.1016/j.lfs.2012.09.025

Vara, D., Morell, C., Rodríguez-Henche, N., and Diaz-Laviada, I. (2013). Involvement of PPARgamma in the antitumoral action of cannabinoids on hepatocellular carcinoma. Cell Death Dis. 4:e618. doi: 10.1038/cddis.2013.141

Vara, D., Salazar, M., Olea-Herrero, N., Guzmán, M., Velasco, G., and DiazLaviada, I. (2011). Anti-tumoral action of cannabinoids on hepatocellular carcinoma: role of AMPK-dependent activation of autophagy. Cell Death Differ. 18, 1099-1111. doi: 10.1038/cdd.2011.32

Velasco, G., Hernández-Tiedra, S., Dávila, D., and Lorente, M. (2016). The use of cannabinoids as anticancer agents. Prog. Neuropsychopharmacol. Biol. Psychiatry. 64, 259-266. doi: 10.1016/j.pnpbp.2015.05.010

Wan, F., Herold-Mende, C., Campos, B., Centner, F. S., Dictus, C., Becker, N., et al. (2011). Association of stem cell-related markers and survival in astrocytic gliomas. Biomarkers 16, 136-143. doi: 10.3109/1354750X.2010.53 6256

Wolfram, R. M., Budinsky, A. C., Brodowicz, T., Kubista, M., Köstler, W. J., Kichler-Lakomy, C., et al. (2000). Defective antigen presentation resulting 
from impaired expression of costimulatory molecules in breast cancer. Int. J. Cancer. 88, 239-244. doi: 10.1002/1097-0215(20001015)88:2<239::AIDIJC15>3.0.CO;2-Z

Xu, X., Liu, Y., Huang, S., Liu, G., Xie, C., Zhou, J., et al. (2006). Overexpression of cannabinoid receptors CB1 and CB2 correlates with improved prognosis of patients with hepatocellular carcinoma. Cancer Genet. Cytogenet. 171, 31-38. doi: 10.1016/j.cancergencyto.2006.06.014

Zheng, D., Bode, A. M., Zhao, Q., Cho, Y. Y., Zhu, F., Ma, W. Y., et al. (2008). The cannabinoid receptors are required for ultraviolet-induced inflammation and skin cancer development. Cancer Res. 68, 3992-3998. doi: 10.1158/00085472.CAN-07-6594

Zhu, L. X., Sharma, S., Stolina, M., Gardner, B., Roth, M. D., Tashkin, D. P., et al. (2000). Delta-9-tetrahydrocannabinol inhibits antitumor immunity by a CB2 receptor-mediated, cytokine-dependent pathway. J. Immunol. 165, 373-380. doi: 10.4049/jimmunol.165.1.373
Zhu, P. J. (2006). Endocannabinoid signaling and synaptic plasticity in the brain. Crit. Rev. Neurobiol. 18, 113-124. doi: 10.1615/CritRevNeurobiol.v18.i $1-2.120$

Conflict of Interest Statement: The authors declare that the research was conducted in the absence of any commercial or financial relationships that could be construed as a potential conflict of interest.

Copyright $\odot 2016$ Ladin, Soliman, Griffin and Van Dross. This is an open-access article distributed under the terms of the Creative Commons Attribution License (CC $B Y)$. The use, distribution or reproduction in other forums is permitted, provided the original author(s) and the copyright owner are credited and that the original publication in this journal is cited, in accordance with accepted academic practice. No use, distribution or reproduction is permitted which does not comply with these terms. 